\title{
Oceanic and atmospheric forcing of Larsen C Ice-Shelf thinning
}

\author{
P. R. Holland ${ }^{1}$, A. Brisbourne ${ }^{1}$, H. F. J. Corr ${ }^{1}$, D. McGrath ${ }^{2,3}$, K. Purdon ${ }^{4}$, J. Paden ${ }^{4}$, H. A. Fricker ${ }^{5}$, F. S. Paolo ${ }^{5}$, and \\ A. H. Fleming ${ }^{1}$ \\ ${ }^{1}$ British Antarctic Survey, Cambridge, UK \\ ${ }^{2}$ USGS Alaska Science Center, Anchorage, Alaska, USA \\ ${ }^{3}$ Cooperative Institute for Research in Environmental Sciences, University of Colorado, Boulder, Colorado, USA \\ ${ }^{4}$ Center for Remote Sensing of Ice Sheets, University of Kansas, Lawrence, Kansas, USA \\ ${ }^{5}$ Scripps Institution of Oceanography, University of California, San Diego, La Jolla, California, USA
}

Correspondence to: P. R. Holland (p.holland@bas.ac.uk)

Received: 9 December 2014 - Published in The Cryosphere Discuss.: 13 January 2015

Revised: 24 March 2015 - Accepted: 27 March 2015 - Published: 13 May 2015

\begin{abstract}
The catastrophic collapses of Larsen A and B ice shelves on the eastern Antarctic Peninsula have caused their tributary glaciers to accelerate, contributing to sea-level rise and freshening the Antarctic Bottom Water formed nearby. The surface of Larsen C Ice Shelf (LCIS), the largest ice shelf on the peninsula, is lowering. This could be caused by unbalanced ocean melting (ice loss) or enhanced firn melting and compaction (englacial air loss). Using a novel method to analyse eight radar surveys, this study derives separate estimates of ice and air thickness changes during a 15-year period. The uncertainties are considerable, but the primary estimate is that the surveyed lowering $\left(0.066 \pm 0.017 \mathrm{~m} \mathrm{yr}^{-1}\right)$ is caused by both ice loss $\left(0.28 \pm 0.18 \mathrm{~m} \mathrm{yr}^{-1}\right)$ and firn-air loss $\left(0.037 \pm 0.026 \mathrm{~m} \mathrm{yr}^{-1}\right)$. The ice loss is much larger than the air loss, but both contribute approximately equally to the lowering because the ice is floating. The ice loss could be explained by high basal melting and/or ice divergence, and the air loss by low surface accumulation or high surface melting and/or compaction. The primary estimate therefore requires that at least two forcings caused the surveyed lowering. Mechanisms are discussed by which LCIS stability could be compromised in the future. The most rapid pathways to collapse are offered by the ungrounding of LCIS from Bawden Ice Rise or ice-front retreat past a "compressive arch" in strain rates. Recent evidence suggests that either mechanism could pose an imminent risk.
\end{abstract}

\section{Introduction}

The ice shelves of the Antarctic Peninsula (AP) have shown a progressive decline in extent over the last 5 decades, including the catastrophic collapses of Larsen A Ice Shelf (LAIS) in 1995 and Larsen B Ice Shelf (LBIS) in 2002 (Scambos et al., 2003; Cook and Vaughan, 2010). The collapse of LBIS was unprecedented in at least the last 12000 years (Domack et al., 2005). These collapses have reduced the restraint of the ice shelves on the flow of grounded tributary glaciers, causing them to accelerate (Rignot et al., 2004; Berthier et al., 2012) and thereby contributing to sea-level rise (Shepherd et al., 2012). Increased freshwater input to the ocean from the collapses and subsequent excess ice discharge may be implicated in the freshening of Antarctic Bottom Water formed nearby (Hellmer et al., 2011; Jullion et al., 2013).

These ice-shelf collapses are thought to have been accomplished by surface meltwater-driven crevassing (van der Veen, 1998; Scambos et al., 2003; van den Broeke, 2005; Banwell et al., 2013) and ice-front retreat past a "compressive arch" in strain rates (Doake et al., 1998; Kulessa et al., 2014). However, longer-term processes such as ice thinning and firn compaction must first have driven these ice shelves into a state liable to collapse by weakening the ice and enabling meltwater to pool on the ice surface. Apparently following the southward progression of ice-shelf instability on the AP, satellite altimetry shows that the surface of Larsen C Ice Shelf (LCIS) has lowered in recent decades (Shepherd et al., 2003; Pritchard et al., 2012; Paolo et al., 2015). The lowering is known to be more rapid in the north of LCIS (Fig. 1; 


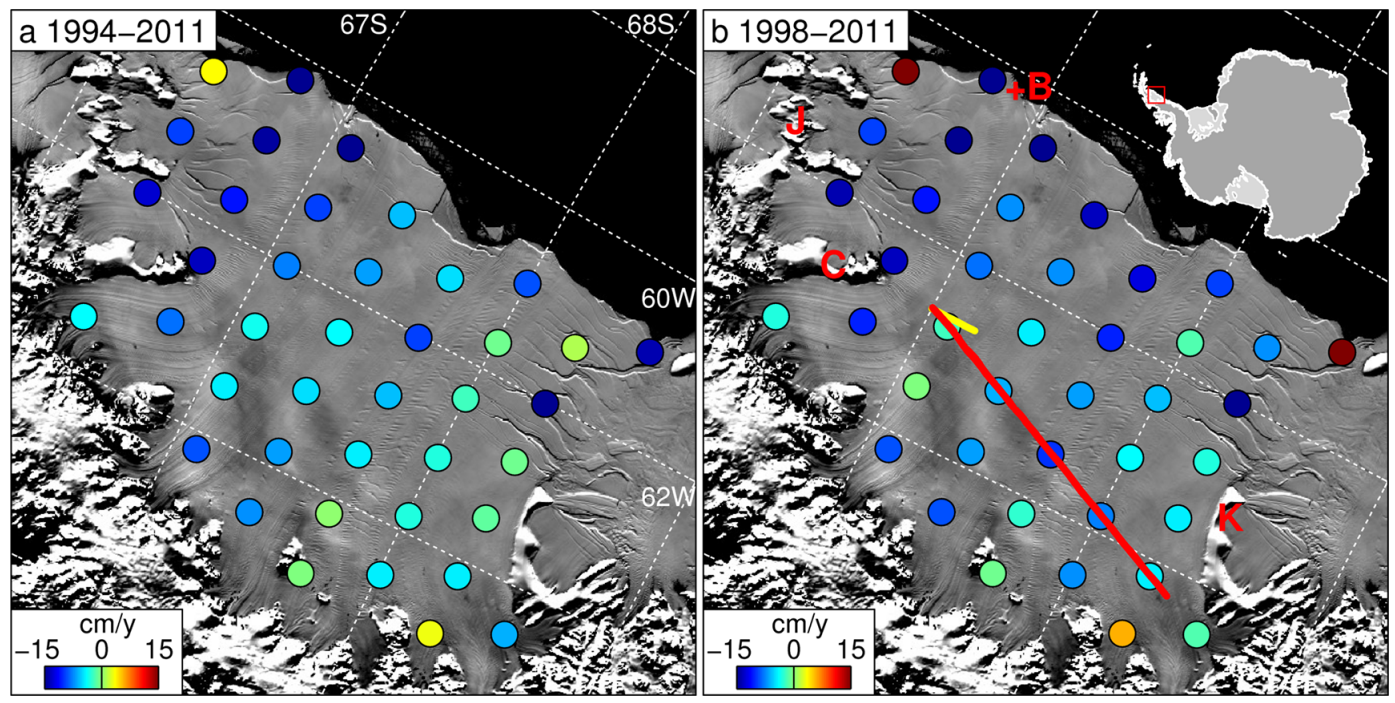

Figure 1. MODIS Mosaic of Antarctica imagery of LCIS (Scambos et al., 2007) showing the location of satellite radar altimeter crossovers and estimated surface lowering rates (updated from Fricker and Padman, 2012, as described in Sect. 2.5) for two periods: (a) 1994-2011, the full period for which ERS-1/2 and Envisat data are reliable, and (b) 1998-2011, the period for which we have radar surveys. The main survey line is shown in red, with the 2012 survey shown in yellow. (b) shows geographical features referred to in the text: B is Bawden Ice Rise; C is Churchill Peninsula; J is Jason Peninsula; K is Kenyon Peninsula.

updated from Fricker and Padman (2012) as described in Sect. 2). Ice flow in this northern region has also accelerated slightly, which may be related to a decrease in backstress from Bawden Ice Rise following an iceberg calving in 2004/2005 (Haug et al., 2010; Khazendar et al., 2011). However, the origin of the lowering remains uncertain. Since the ice shelf is floating, the lowering could be caused by a loss of firn air of nearly the same magnitude, a loss of solid ice approximately 10 times larger, or a combination of the two. With recent evidence of unusual rifting apparently threatening the stability of LCIS (Jansen et al., 2015), there is an urgent need to understand the cause of this long-term lowering in order to project the future of LCIS and the impacts of its many glacier catchments upon sea-level rise and ocean freshening.

The LCIS lowering was initially attributed to increased oceanic basal melting (i.e. ice loss) on the basis that firn compaction from derived surface melting trends was insufficient to account for the signal (Shepherd et al., 2003). However, sparse observations of the ocean beneath LCIS found the ocean to be at or below the sea-surface freezing temperature, suggesting that it is only capable of slow melting (Nicholls et al., 2012). Observations of the meltwater emanating from the cavity (Nicholls et al., 2004) and widespread marine ice in LCIS (Holland et al., 2009; Jansen et al., 2013; McGrath et al., 2014) suggest that these temperatures are spatially and historically prevalent. Ocean waters entering the LCIS cavity appear to be constrained to the surface freezing temperature by nearby sea-ice formation. Since the Weddell Sea has consistently high rates of sea-ice production it has been regarded as hard to conceive of an ocean warming sufficient to increase melting enough to explain the lowering (Nicholls et al., 2004). However, year-round sonar measurements near Kenyon Peninsula in the south of LCIS yield a mean melt rate of $\sim 0.8 \mathrm{~m} \mathrm{yr}^{-1}$ (with a range of $0-1.5 \mathrm{~m} \mathrm{yr}^{-1}$ ), which is significantly higher and more variable than expected (K. W. Nicholls, personal communication 2014; Nicholls et al., 2012). Furthermore, ocean data collected in January 1993 from the LCIS ice front (Bathmann et al., 1994) show anomalous waters that are considerably warmer than any subsequently observed in the cavity or inferred as sources for melting (Nicholls et al., 2004, 2012). If they entered the cavity, such warm waters could produce a melting anomaly large enough to significantly perturb the LCIS ice mass budget. Given our incomplete understanding of ocean processes and melting beneath LCIS, oceanic thinning of LCIS remains a credible explanation for the lowering.

However, there is some evidence supporting a hypothesis that the lowering results from an atmosphere-driven increase in firn compaction (i.e. air loss) through either dry compaction or firn melting and refreezing. In general, the AP has experienced strong atmospheric warming since the 1950s (Marshall et al., 2006; Turner et al., 2014). A spatial correspondence between ice-shelf collapses and mean atmospheric temperature suggests that atmospheric warming may have pushed some ice shelves beyond a thermal limit of viability (Morris and Vaughan, 2003); the northern edge of LCIS is at this limit. Observations of LCIS firn-air thickness confirm that there is sufficient firn air available for compaction, that lower firn air spatially corresponds with higher melting, and that the northward-intensified surface lowering spatially corresponds to areas of high melting and firn compaction 
Table 1. Details of the radio-echo sounding and altimeter surveys used in this analysis.

\begin{tabular}{lllll}
\hline Date & Origin & Platform & Ice-sounding radar & $\begin{array}{l}\text { Ice } \\
\text { elevation }\end{array}$ \\
\hline 20 Feb 1998 & BAS-Argentine & Twin Otter & $150 \mathrm{MHz}^{\mathrm{a}}$ & radar altimeter $^{\mathrm{a}}$ \\
26 Nov 2002 & NASA-CECS & P-3 & ICORDS2 140-160 MHz $^{\mathrm{b}}$ & laser ATM $^{\mathrm{c}}$ \\
29 Nov 2004 & NASA-CECS & P-3 & ACORDS 140-160 MHz & laser ATM $^{\mathrm{b}}$ \\
4 Nov 2009 & NASA IceBridge & DC-8 & MCoRDS 190-200 MHz $^{*}$ b,d & laser ATM $^{\mathrm{c}}$ \\
19-21 Nov 2009 & McGrath & Sledge & $25 \mathrm{MHz}^{\mathrm{e}}$ & GPS $^{\mathrm{e}}$ \\
13 Nov 2010 & NASA IceBridge & DC-8 & MCoRDS 190-200 MHz & laser ATM \\
27 Jan 2011 & BAS & Twin Otter & $150 \mathrm{MHz}$ & radar altimeter $^{\mathrm{c}}$ \\
13-14 Dec 2012 & Brisbourne & Sledge & $50 \mathrm{MHz}$ & GPS \\
\hline
\end{tabular}

${ }^{a}$ Holland et al. (2009); ${ }^{\text {b }}$ https://data.cresis.ku.edu/\#RDS; ${ }^{\mathrm{c}}$ http://nsidc.org/data/ilatm2; ${ }^{\mathrm{d}}$ http://nsidc.org/data/irmcr2.html; ${ }^{\mathrm{e}}$ McGrath et al. (2014); ${ }^{*}$ Data neglected due to transmit/receive switch problem, see Sect. 2.3.

(Holland et al., 2011; Trusel et al., 2013; Luckman et al., 2014). Modelled firn compaction entirely offset the lowering in one study of 2003-2008 (Pritchard et al., 2012), albeit with a high uncertainty. A temporal correspondence between high annual melting and ice-shelf collapse (van den Broeke, 2005) would be expected to hold also for firn compaction before collapse. However, attributing the lowering to simple atmospheric temperature trends is not straightforward. Observed AP surface melt days and modelled meltwater fluxes both lack significant trends during 1979-2010 and have trends that are strongly negative during 1989-2010 (Kuipers Munneke et al., 2012a). An automatic weather station on LCIS lacks any significant 1985-2011 trend in air temperature in any season (Valisuo et al., 2014), and there is no convincing evidence of trends in melting derived from reanalysis models during recent decades (Valisuo et al., 2014). Even without a trend in atmospheric forcing within recent decades, the period could still be anomalous relative to the long-term mean, and so an atmosphere-driven lowering remains viable.

In summary, there is a wealth of circumstantial evidence related to the lowering but no direct test of its origin. In this study we analyse repeated radio-echo sounding surveys of LCIS, applying a novel method to separate changes in ice thickness from changes in firn-air thickness (Holland et al., 2011). The method is presented in Sect. 2 and its results in Sect. 3. We then consider whether the uncertainties in these ice and air trends are sufficiently well constrained to isolate the origin of the LCIS lowering (Sect. 4) and speculate upon the prognosis for the ice shelf's future stability (Sect. 5).

\section{Method}

Radar sounding provides the two-way travel time (TWTT) of a radar wave between the ice-shelf surface and base. This can be combined with accurate measurements of surface elevation to derive separate thicknesses of the solid ice and englacial firn air that comprise a floating ice shelf (Holland et al., 2011). With multiple surveys it is therefore possible to determine differences in ice and air thickness over time. There have been many radar surveys of LCIS, but we find that a very large number of observations are needed to sufficiently reduce the random error in the ice and air differences. Therefore, only repeated survey lines provide usable data; inter-survey crossovers are not sufficient. Fortunately, a nearly meridional (across-ice flow) survey line sampling the centre of LCIS has been occupied eight times between 1998 and 2012 by airborne and ground-based radar surveys (Fig. 1b, Table 1), offering the opportunity to derive interannual trends in ice and air thickness from these data. The survey line also passes through five satellite crossovers of European Space Agency radar altimeter missions, allowing direct comparison to the known lowering.

\subsection{Theory}

We separate the total ice-shelf thickness into its constituent thicknesses of solid ice and firn air by following the method of Holland et al. (2011) with a few modifications. Since the floatation of an ice shelf and the propagation of a radar wave through an ice shelf both depend upon the relative proportions of ice and air, we formulate two corresponding equations from which two unknown quantities, ice and air thickness, are derived. The presence of a third unknown, liquid meltwater, is neglected on the basis that most surveys were undertaken early in the austral spring and there is no evidence of a perennial aquifer in LCIS (see Sect. 4.3).

If the ice is freely floating then the hydrostatic ice and ocean forces must balance at the ice base, so the total mass of the shelf ice and firn air equals that of the atmosphere and ocean displaced

$\rho_{\mathrm{i}} I+\rho_{\mathrm{a}} A=\rho_{\mathrm{A}} S+\rho_{\mathrm{o}}(I+A-S)$.

Here $I$ is the total solid ice thickness, $A$ is the total firnair thickness, $S$ is the ice-shelf freeboard (surface elevation above sea level), and $\rho_{\mathrm{i}}=918 \mathrm{~kg} \mathrm{~m}^{-3}, \rho_{\mathrm{a}}=2 \mathrm{~kg} \mathrm{~m}^{-3}$, $\rho_{\mathrm{A}}=1.3 \mathrm{~kg} \mathrm{~m}^{-3}$, and $\rho_{\mathrm{o}}=1028 \mathrm{~kg} \mathrm{~m}^{-3}$ are densities of solid ice, englacial air (partly pressurised), atmospheric air, 
and ocean respectively, which are all assumed constant. Adopting a similar approach and separating the radar delay of ice from that of air using the simple, empirical complex refractive index method (e.g. Arcone, 2002), the TWTT of a radar wave through the ice shelf is

$T=\frac{2}{c}\left(n_{\mathrm{i}} I+n_{\mathrm{a}} A\right)$,

where $T$ is the TWTT, $c=3 \times 10^{8} \mathrm{~m} \mathrm{~s}^{-1}$ is the speed of light in vacuo, and $n_{\mathrm{i}}=1.78$ and $n_{\mathrm{a}}=1.0$ are refractive indices of pure ice and air. Combining Eqs. (1) and (2) and eliminating variables as appropriate, we obtain expressions for the constituent ice and air thicknesses (and hence total thickness, $I+A)$ as functions of known quantities and the measured TWTT and surface elevation:

$$
\begin{aligned}
A= & {\left[\frac{c\left(\rho_{\mathrm{o}}-\rho_{\mathrm{i}}\right)}{2 n_{\mathrm{i}}} T+\left(\rho_{\mathrm{A}}-\rho_{\mathrm{o}}\right) S\right] / } \\
& {\left[\left(\rho_{\mathrm{a}}-\rho_{\mathrm{o}}\right)+\frac{n_{\mathrm{a}}\left(\rho_{\mathrm{o}}-\rho_{\mathrm{i}}\right)}{n_{\mathrm{i}}}\right] } \\
I= & {\left[\frac{c\left(\rho_{\mathrm{o}}-\rho_{\mathrm{a}}\right)}{2 n_{\mathrm{a}}} T+\left(\rho_{\mathrm{A}}-\rho_{\mathrm{o}}\right) S\right] / } \\
& {\left[\left(\rho_{\mathrm{i}}-\rho_{\mathrm{o}}\right)+\frac{n_{\mathrm{i}}\left(\rho_{\mathrm{o}}-\rho_{\mathrm{a}}\right)}{n_{\mathrm{a}}}\right] . }
\end{aligned}
$$

Taking the temporal derivative of these expressions, we obtain the trends in ice and air thickness as a function of the trends in elevation and TWTT:

$$
\begin{aligned}
\frac{\partial A}{\partial t}= & {\left[\frac{c\left(\rho_{\mathrm{o}}-\rho_{\mathrm{i}}\right)}{2 n_{\mathrm{i}}} \frac{\partial T}{\partial t}+\left(\rho_{\mathrm{A}}-\rho_{\mathrm{o}}\right) \frac{\partial S}{\partial t}\right] / } \\
& {\left[\left(\rho_{\mathrm{a}}-\rho_{\mathrm{o}}\right)+\frac{n_{\mathrm{a}}\left(\rho_{\mathrm{o}}-\rho_{\mathrm{i}}\right)}{n_{\mathrm{i}}}\right] } \\
\frac{\partial I}{\partial t}= & {\left[\frac{c\left(\rho_{\mathrm{o}}-\rho_{\mathrm{a}}\right)}{2 n_{\mathrm{a}}} \frac{\partial T}{\partial t}+\left(\rho_{\mathrm{A}}-\rho_{\mathrm{o}}\right) \frac{\partial S}{\partial t}\right] / } \\
& {\left[\left(\rho_{\mathrm{i}}-\rho_{\mathrm{o}}\right)+\frac{n_{\mathrm{i}}\left(\rho_{\mathrm{o}}-\rho_{\mathrm{a}}\right)}{n_{\mathrm{a}}}\right] . }
\end{aligned}
$$

Hence, we calculate ice and air trends directly from elevation and TWTT trends; we do not derive the ice and air thickness for each survey and then calculate their trends. This explicitly excludes potentially large errors inherent in steady corrections to the input data, particularly from the geoid and mean dynamic ocean topography. Evaluating the known quantities in Eqs. (5)-(6), we find that

$$
\begin{aligned}
& \frac{\partial A}{\partial t}=1.06 \frac{\partial S}{\partial t}-0.114 \frac{c}{2 n_{\mathrm{i}}} \frac{\partial T}{\partial t} \\
& \frac{\partial I}{\partial t}=-0.598 \frac{\partial S}{\partial t}+1.06 \frac{c}{2 n_{\mathrm{i}}} \frac{\partial T}{\partial t},
\end{aligned}
$$

where the TWTT is expressed as a solid ice equivalent for clarity.
Note that the derivation of Eqs. (5)-(6) from Eqs. (3)-(4) neglects temporal derivatives of all densities, of which the most variable is the ocean density. Repeating the derivation and retaining ocean density terms provides an expression in which $0.3 \mathrm{~m} \mathrm{yr}^{-1}$ ice loss would require a $\sim 2 \mathrm{~kg} \mathrm{~m}^{-3} \mathrm{yr}^{-1}$ reduction in ocean density, and $0.03 \mathrm{~m} \mathrm{yr}^{-1}$ air loss would require a $\sim 0.1 \mathrm{~kg} \mathrm{~m}^{-3} \mathrm{yr}^{-1}$ increase in ocean density. Such changes persisting over 15 years are clearly implausible, and we conclude that ocean density changes have negligible effect.

\subsection{Application to Larsen C Ice Shelf}

We apply the above method to eight radar surveys between February 1998 and December 2012 along a line traversing the centre of LCIS (Fig. 1b, red line). The surveys were carried out by ground-based field parties and a variety of aircraft flying at different heights and speeds, and many different radar instruments and methods for measuring elevation were used (Table 1). The processed elevation and TWTT data are shown in Fig. 2a and b. The most densely spaced TWTT data were gathered during the 2004 NASA-CECS airborne survey, so this is chosen as a baseline data set. For each elevation and TWTT measurement in the other surveys, we find the difference from the nearest corresponding measurement in the 2004 survey, discarding all observations that do not have a 2004 analogue within $1000 \mathrm{~m}$. These elevation and TWTT differences are shown in Fig. $2 \mathrm{c}$ and d. There is a great deal of scatter in the differences, which could result from several factors, including the advection of ice topography across the survey line at $\sim 400 \mathrm{~m} \mathrm{yr}^{-1}$ (Rignot et al., 2011). The differences are therefore binned spatially to extract the overall signals by averaging random noise, and linear trends in surface elevation and TWTT are calculated for the bins. Equations (5) and (6) are then used to determine the trends in ice and firn-air thickness from trends in surface elevation and TWTT. We apply this methodology in two ways: first considering the overall trends for the entire survey line and then dividing the survey into five bins, surrounding each of the five satellite crossover points (Fig. 1).

The 2012 British Antarctic Survey (BAS) ground-based survey was a mission of opportunity within a wider seismic season (Brisbourne et al., 2014) and deviated from the rest of the surveys, heading due south (Fig. 1b, yellow line). However, it did repeat a flight line from the 1998 BAS airborne survey, so to include the data we first calculate the mean difference between the 2012 and 1998 surveys along the meridional line, and then the mean difference between the 2004 and 1998 surveys along the primary line, then use these to obtain the 2012-2004 difference. The results are only included in the northernmost bin when we consider along-survey variability; they are not included in the whole-survey results. 

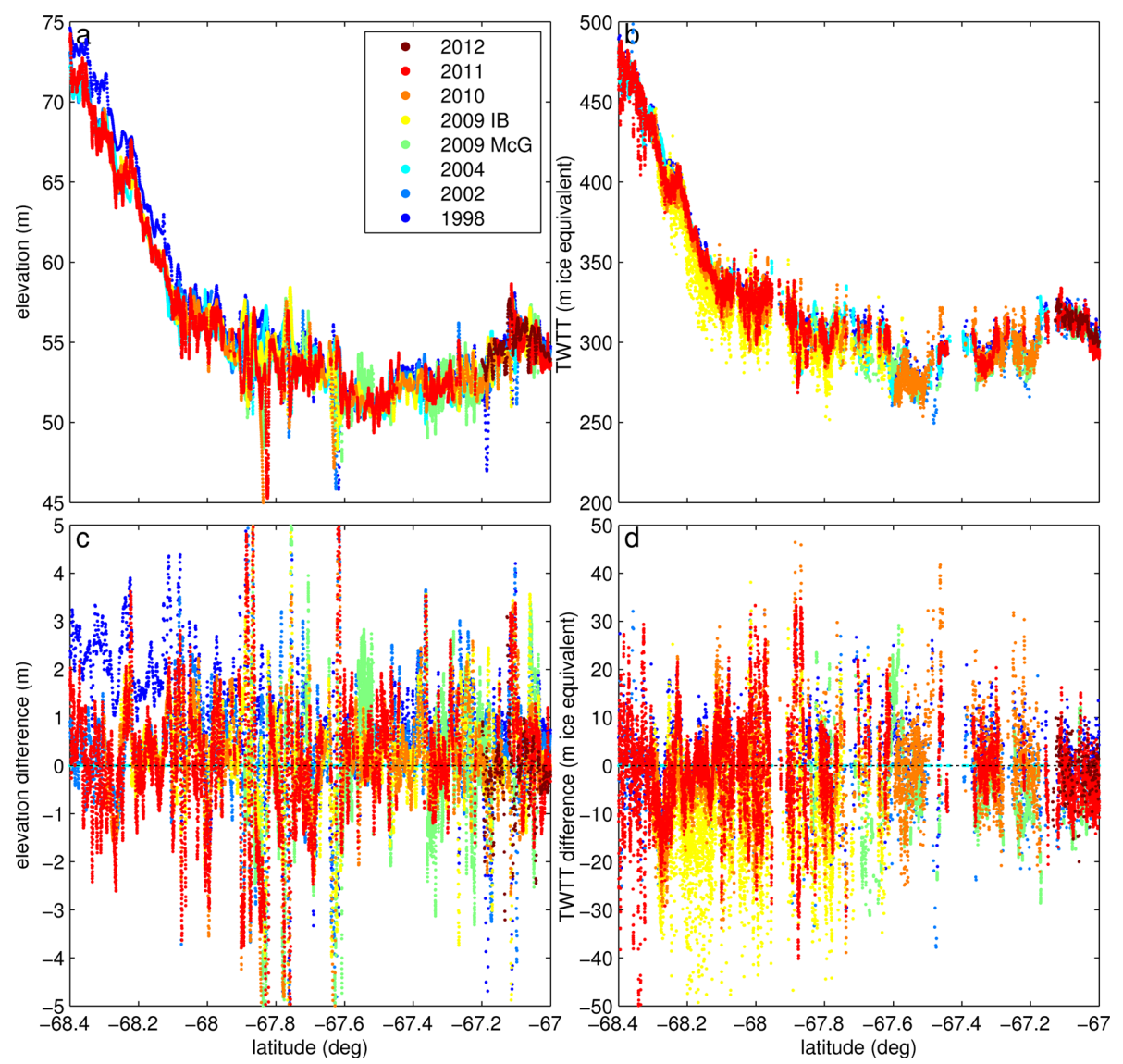

Figure 2. Processed data from the eight surveys from which the air and ice thickness changes are derived. (a) Surface elevation relative to WGS84 ellipsoid. (b) Radar two-way travel time (TWTT), expressed as an equivalent thickness of solid ice. (c) Difference between each elevation observation and nearest 2004 analogue. (d) Difference between each TWTT observation and nearest 2004 analogue.

\subsection{Radio-echo sounding survey data}

Different techniques are available for picking radar return echoes from echograms, and so to ensure that our intersurvey trends are as robust as possible the ice surface and base echoes from all surveys were re-picked in a consistent manner. Automatic first-break picks on time-windowed and scaled traces were manually edited to remove or correct mispicks. For airborne surveys, TWTT was calculated as the difference between ice surface and basal returns from the icepenetrating radar, thus minimising inter-survey biases by removing any error associated with the absolute accuracy of the radar. Basal return TWTTs from the ground-based survey data were corrected for the radar antenna separation. In the NASA IceBridge 2009 and 2010 and BAS 2011 airborne surveys, the altitude of the aircraft in specific sections caused the surface multiple return to appear at a TWTT similar to that of the basal return, significantly contaminating the picks. Therefore, the radargrams were overlain with an estimate of the surface multiple return calculated from the aircraft altitude and also an estimate of the basal return derived from the aircraft altitude, surface elevation, and hydrostatic assumption.
Wherever the TWTT of these two signals was indistinguishable in the radargram, no basal return pick was recorded. Significant marine ice bands were omitted from all surveys, because basal returns become indistinct and the meteoricmarine transition may be visible instead.

The TWTT data are recorded with a wide variety of instruments and subject to different processing techniques to optimise the signal prior to picking. The TWTT precision in the echogram picked (i.e. the time between samples of return power: the reciprocal of the sampling rate) varies between surveys, with a mean of $\sim 4 \mathrm{~m}$ ice equivalent and a range of $0.13-8.8 \mathrm{~m}$ ice equivalent. The 15 -year TWTT change is of comparable magnitude to this precision (see below). However, the first break of the return echo is actually known at higher precision because waveform fitting is used to interpolate between samples of the return echo power. Furthermore, each inter-survey TWTT difference, from which ice and air trends are calculated, is actually the mean of a population of thousands of individual point differences. These populations are well resolved by the TWTT precision, and so by using large numbers of data points we are able to detect mean inter- 
survey differences statistically at a precision much finer than that of the individual data.

TWTTs from the 2009 IceBridge survey were found to contain consistently shorter radar-wave delays than the 2009 McGrath ground-based survey despite being collected only 2 weeks earlier, with a mean equivalent ice thickness approximately $10 \mathrm{~m}$ lower and therefore a significant outlier relative to the other surveys. The data were investigated and repicked, but the problem seems to result from transmit/receive switches not meeting their switching-time specification in the survey (https://data.cresis.ku.edu/\#RDS). Therefore, the 2009 IceBridge TWTT data are neglected throughout this study, other than in a test recalculation to demonstrate their effect. The laser altimeter elevation data from this survey are used in all calculations.

\subsection{Surface elevation survey data}

Surveyed ice elevation data have several corrections applied to make them directly comparable. Corrections for the steady geoid and mean dynamic ocean topography are not required because the method employs only temporal differences in elevation, as shown by Eqs. (5) and (6). All data are detided using the CATS2008a_opt model (L. Padman, personal communication, 2014) and have a local sea-level rise of $4 \mathrm{~mm} \mathrm{yr}^{-1}$ removed (Rye et al., 2014).

Most of the instruments used to derive elevation were well calibrated in the field (e.g. http: //nsidc.org/data/docs/daac/icebridge/ilatm2/index.html),

but the two BAS airborne surveys in 1998 and 2011 were not calibrated to the centimetre-scale accuracy required here. The 1998 survey passed over the open ocean in many locations, so these elevations were corrected for tides, EIGEN-6C geoid (http: //icgem.gfz-potsdam.de/ICGEM/ICGEM.html), and DTU12 mean dynamic topography (http://www.space.dtu.dk/ english/Research/Scientific_dataandmodels/downloaddata), and then the mean difference from 0 (sea surface) of $1.01 \mathrm{~m}$ was removed from the entire data set. Repeating this procedure for the 2011 survey produced a $1.33 \mathrm{~m}$ offset but from only a small area of open-ocean data. Fortunately, it was possible to correct the 2011 elevations to match the well-calibrated 2010 NASA IceBridge laser altimeter survey that took place 10 weeks earlier. However, this was complicated by the issue of radar firn penetration. Radar altimetry penetrates the surface and reflects from within the firn layer, whereas laser altimetry reflects from the surface. North of $67.85^{\circ} \mathrm{S}$ there is no broad-scale spatial variation in the offset between data sets (Fig. 3), implying either uniform or no radar penetration. We regard the mean offset in this area, $1.59 \mathrm{~m}$, as the calibration error and subtract it from the 2011 data everywhere.

The elevation estimates derived from the two BAS radar altimeter surveys need a firn-penetration correction to make them comparable to those derived from the laser altimeters

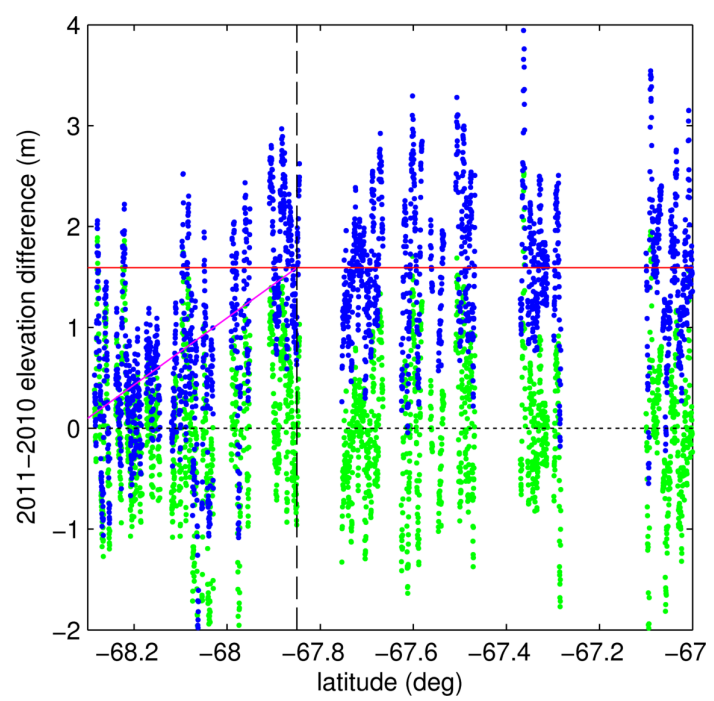

Figure 3. Correction of the elevation data in the 2011 BAS airborne survey. Blue dots show the differences between uncorrected BAS radar altimetry elevations on 27 January 2011 and IceBridge laser altimetry elevations on 13 November 2010 (using the sign convention 2011 minus 2010). The 2011 survey data need to be calibrated and also have radar firn penetration removed. Assuming negligible elevation change over the $\sim 10$ weeks between surveys, the 2011 data are first calibrated by subtracting everywhere an offset of $1.59 \mathrm{~m}$ (red line; the mean difference from 2010 for all data north of $67.85^{\circ} \mathrm{S}$ ). After this calibration, the 2011 data are progressively lower than 2010 south of $67.85^{\circ} \mathrm{S}$, which is attributed to radar penetration of the firn (Holland et al., 2011). In this region we add an additional penetration correction equal to the difference between the red and magenta lines. This correction is also applied to the 1998 BAS radar altimeter data. Green dots show the difference between the corrected 2011 data and the 2010 data.

and GPS. After the above calibration, the 2011 radar altimeter survey records a progressively lower surface than the 2010 laser altimeter survey to the south of $67.85^{\circ} \mathrm{S}$, which we ascribe to firn penetration. This is qualitatively consistent with the known southward increase in firn-air content (Holland et al., 2011). Therefore, we correct both the 1998 and 2011 radar altimeter surveys by adding a linear fit south of $67.85^{\circ} \mathrm{S}$ to the difference between the IceBridge 2010 and BAS 2011 surveys (Fig. 3). Out of necessity, the correction includes implicit assumptions that there is no firn penetration north of this during either radar survey and that penetration to the south is identical in February 1998 and January 2011.

\subsection{Satellite radar altimeter elevation data}

Satellite radar altimeter data are used to corroborate the surveyed elevation data and provide a context for the lowering. The satellite elevation time series combine radar altimeter data from the ERS-1, ERS-2, and Envisat satellites using an existing methodology (Fricker and Padman, 2012) but including new data to the end of 2011. These data consist of 
Table 2. Elevation and TWTT trends and their derived ice and air trends from calculations performed using different combinations of data. TWTT trends are expressed as solid-ice thickness equivalent. Trends in bold are smaller than the derived uncertainty (see main text).

\begin{tabular}{lcccc}
\hline Case & $\begin{array}{c}\text { Elevation } \\
\left(\mathrm{m} \mathrm{yr}^{-1}\right)\end{array}$ & $\begin{array}{c}\text { TWTT } \\
\left(\mathrm{m} \mathrm{ice} \mathrm{yr}^{-1}\right)\end{array}$ & $\begin{array}{c}\text { Ice } \\
\left(\mathrm{m} \mathrm{yr}^{-1}\right)\end{array}$ & $\begin{array}{c}\text { Air } \\
\left(\mathrm{m} \mathrm{yr}^{-1}\right)\end{array}$ \\
\hline Reference & -0.0660 & -0.296 & -0.274 & -0.0367 \\
\hline Using satellite altimetry & -0.0616 & -0.296 & -0.277 & -0.0320 \\
BAS only & -0.0752 & -0.264 & -0.235 & -0.0500 \\
NASA only & -0.0303 & $\mathbf{0 . 0 8 7}$ & $\mathbf{0 . 1 1 0}$ & -0.0421 \\
\hline Without 1998 & -0.0311 & $\mathbf{- 0 . 0 4 1}$ & $\mathbf{- 0 . 0 2 5}$ & -0.0285 \\
Without 2002 & -0.0694 & -0.389 & -0.371 & -0.0297 \\
Without 2004 & -0.0713 & -0.281 & -0.256 & -0.0439 \\
Without 2009 MG & -0.0654 & -0.195 & $\mathbf{- 0 . 1 6 8}$ & -0.0474 \\
Without 2010 & -0.0648 & -0.351 & -0.334 & -0.0290 \\
Without 2011 & -0.0695 & -0.394 & -0.377 & -0.0292 \\
\hline With 2009 IB TWTT & -0.0660 & -0.482 & -0.471 & $\mathbf{- 0 . 0 1 5 5}$ \\
With 2012 & -0.0670 & -0.212 & -0.185 & -0.0473 \\
\hline Uncertainty (see text) & 0.017 & 0.17 & 0.18 & 0.026 \\
\hline
\end{tabular}

a All 1998 and 2011 data. $^{\text {b }}$ All 2002, 2004, 2010 data and elevation for IceBridge 2009.

repeat measurements of ice-shelf surface elevation at satellite orbit crossing points, available approximately every 35 days during austral winters (April-November) during 1992-2011.

When analysing the data we found a strong correlation between changes in elevation and changes in surface backscatter for the period 1992-1993 (the first 2 years of ERS-1). This anomalous behaviour in the altimeter backscatter, which alters the shape of the waveform from which the elevation is deduced, occurs throughout Antarctica. This leads us to believe that these data may not be reliable, so we only use data from 1994 onwards in this study. Shepherd et al. (2010) and Paolo et al. (2015) also neglected data prior to 1994 in their analyses. This is important because studies of LCIS that include these early data (Shepherd et al., 2003; Fricker and Padman, 2012) derive very rapid lowering in the 1990s that is not found if the early data are neglected. To illustrate the lowering of LCIS we first consider the period 1994-2011 (Fig. 1a), though our main analysis focuses upon the 19982011 period covered by the radar surveys (Fig. 1b). During the latter period the LCIS lowering has the same general pattern, but the trends at the five crossovers covered by the survey line are slightly different. Importantly, the survey line does not sample the northern section of LCIS in which the fastest lowering occurs.

To compare elevation trends derived from the survey data to those derived from satellite radar altimeter data (Fig. 4 and Table 2) a single satellite elevation trend was derived that represents all five independent satellite crossovers. First, the mean elevation for the austral winter of 1998 was calculated for each independent crossover and subtracted from each crossover's time series. The resulting temporal elevation anomaly data were then treated as individual data points in a single merged time series, and from that a linear trend was calculated to compare to the surveyed trends. Linear trends were also calculated at each crossover, as presented in Figs. 1, 5, 6, and 7.

\subsection{Ice and air mass balances}

We consider the derived ice and air losses in the context of the ice and air mass balances of LCIS. The mass balance of the ice fraction of the ice shelf (i.e. excluding firn air) yields an equation governing the depth-integrated ice thickness

$\frac{\partial I}{\partial t}+I \nabla \cdot \boldsymbol{u}+\boldsymbol{u} \cdot \nabla I=a_{\mathrm{I}}-m_{\mathrm{I}}$

where $\boldsymbol{u}$ is the two-dimensional horizontal ice velocity vector, $a_{\mathrm{I}}$ is net surface ice accumulation, and $m_{\mathrm{I}}$ is basal melting. The mass balance of the air fraction of the ice shelf yields a similar equation for depth-integrated air thickness

$\frac{\partial A}{\partial t}+A \nabla \cdot \boldsymbol{u}+\boldsymbol{u} \cdot \nabla A=a_{\mathrm{A}}-m_{\mathrm{A}}-d$,

where $a_{\mathrm{A}}$ is the air trapped in the firn by accumulation, $m_{\mathrm{A}}$ is the loss of air by surface melting, percolation, and refreezing, and $d$ is the loss of air by dry compaction. The terms on the left-hand side of both equations are the unsteady term, divergence, and advection.

When analysing the results we map the terms in the ice mass balance Eq. (9) following a previous study (McGrath et al., 2014) that combined data from several sources. Divergence, advection, and mass input terms can be mapped from satellite-based observations of ice velocity (Rignot et al., 2011) and ice-shelf elevation (Griggs and Bamber, 2009), 


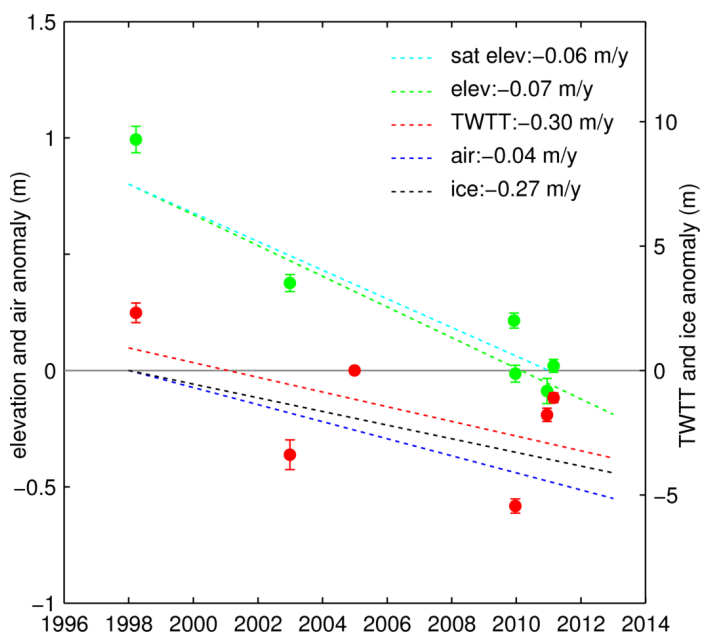

Figure 4. Inter-survey differences in elevation, TWTT, ice, and air. Mean differences between each survey and 2004 for elevation are shown in green and for TWTT (ice equivalent) in red. Error bars represent $95 \%$ confidence intervals of the population of differences from 2004, and dashed lines represent linear trend lines. The 2004 elevation and TWTT are both shown as 0 , with 0 error. The elevation trend derived from satellite radar altimetry is also shown in cyan. Trends in ice thickness (black) and air thickness (blue) are derived directly from trends in TWTT and elevation, revealing that LCIS has lost both ice and air over the period surveyed. Elevation and air thickness use the left axis, while TWTT and ice thickness are plotted with absolute values on the right axis and equivalent surface elevation on the left axis.

firn-air thickness derived from airborne radar measurements (Holland et al., 2011), and model estimates of net surface accumulation (Lenaerts et al., 2012). Though we also possess a spatial map of ice surface elevation change, an unknown fraction of this is caused by firn-air changes and so we cannot derive ice thickness change outside the temporal and spatial range of our survey data. Neglecting the unsteady term, we can derive a map of steady-state melting from the other terms. Prior to these calculations the ice thickness and velocity fields are smoothed over a $20 \mathrm{~km}$ footprint (masked outside the ice shelf) to remove small-scale noise that is amplified in the spatial derivatives. The firn-air mass balance Eq. (10) contains so many unknown quantities that we do not attempt to derive its terms.

\section{Results}

We first present the main results of the study before a full analysis of the uncertainties in Sect. 4.

\subsection{Trends over the whole survey line}

Figure 4 shows the elevation and TWTT for each survey as mean differences from 2004 over the entire survey line, and Table 2 gives the "primary" derived trends for these "refer- ence" data and also a variety of alternatives. Since the data points and their error bars refer to differences from 2004, the 2004 data are 0 for both elevation and TWTT, with 0 error. The surveyed elevation differences show a lowering trend $\left(-0.066 \pm 0.017 \mathrm{~m} \mathrm{yr}^{-1}\right)$ that is very similar to that obtained from the satellite altimeter data $\left(-0.062 \mathrm{~m} \mathrm{yr}^{-1}\right)$; the trends are not expected to be identical due to method uncertainties and spatial and temporal differences in sampling. Crucially, there is also a decreasing trend in surveyed TWTT $\left(-0.296 \pm 0.17 \mathrm{~m} \mathrm{yr}^{-1}\right.$ ice equivalent), though there is considerably more inter-survey scatter in this quantity and uncertainty in the resulting trend (see Sect. 4.3). Combining these observed trends using Eqs. (5) and (6) reveals that the surface lowering is caused by a combination of air loss $\left(-0.0367 \pm 0.026 \mathrm{~m} \mathrm{yr}^{-1}\right)$ and ice loss $\left(-0.274 \pm 0.18 \mathrm{~m} \mathrm{yr}^{-1}\right)$. Ice loss is an order of magnitude larger than air loss, but surface lowering is approximately 10 times more sensitive to air loss than ice loss, so ice and air loss contribute approximately equally to the surface lowering. There is considerable scatter in the data and several sources of uncertainty in the methodology, but our conclusion that ice and air loss both contribute to the lowering is robust when several different combinations of data are used in the calculations (see Sect. 4).

\subsection{Variation within survey line}

We now consider spatial variability by binning the survey data around each satellite crossover (Fig. 5a). The derived ice loss is reasonably uniform along the line, while the derived air loss is noticeably higher towards the southern end of the survey line. However, the surveyed elevation trends at the southern end of the line show considerably more lowering than the satellite elevation trends. Inspection of the data underlying the time series in each bin (Fig. 6) reveals that the surveyed elevations are reasonable apart from the 1998 data in the southernmost bin (centred on $68.3^{\circ} \mathrm{S}$ ), which exceed the range of the figure. We consider the satellite altimeter data to be a more reliable measure of lowering because the 1998 surveyed elevation data are subject to calibration and firn-penetration corrections that are uncertain in this area (see Sect. 2.4). The TWTT data are not subject to these uncertain corrections, so we retain these and recalculate the ice and air trends with the surveyed elevation trends replaced by the satellite elevation trends (Fig. 7a). This has virtually no effect on the derived ice loss but removes the air loss completely from the southernmost bin, so that the air loss is concentrated on the centre of the survey line.

The air and ice losses shown in Figs. 5a and 7a are scaled so that their resultant surface lowering can be read on the lefthand axis. Figure 7 a suggests that air loss contributes the majority of the lowering in the centre of the survey line, while ice loss also contributes to this lowering and is responsible for the lowering at both ends. It is unsurprising that the ice 

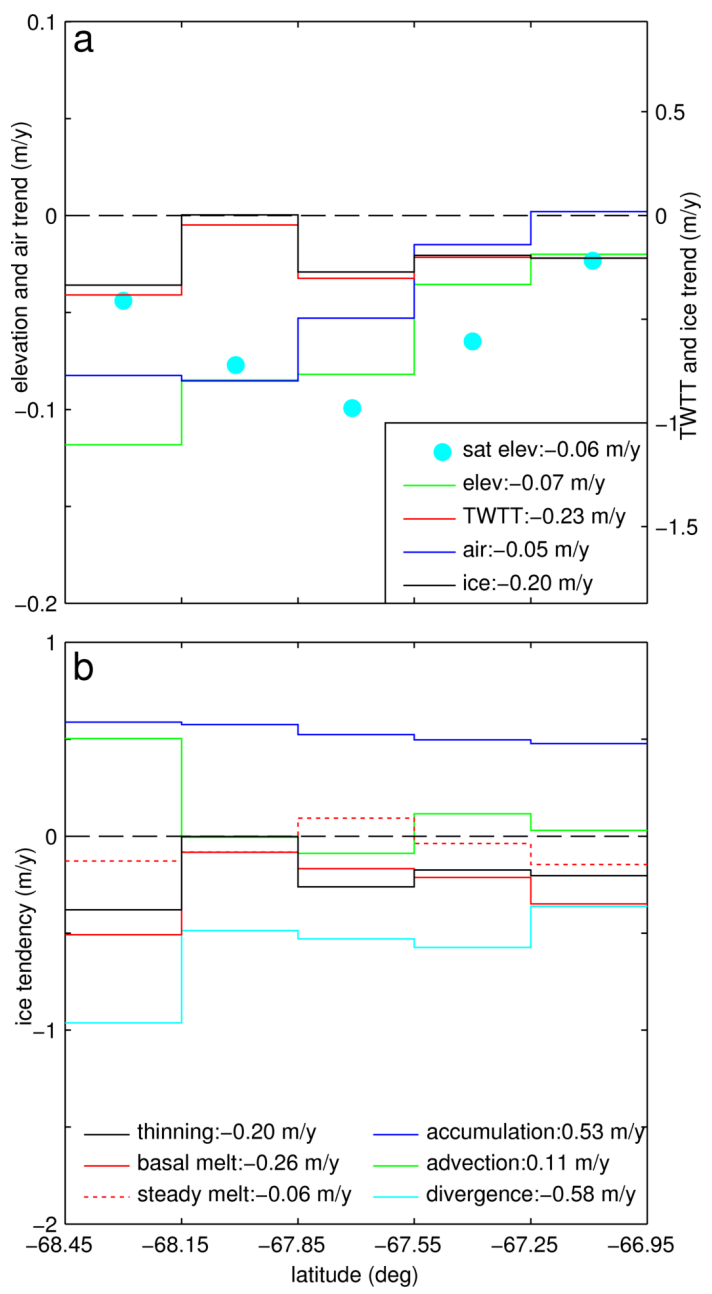

Figure 5. Spatial variation in derived quantities along the survey line within latitude bins centred on the locations of the satellite crossover points (see Fig. 1b). (a) Trends in elevation (green), TWTT (red; ice equivalent), and air (black) and ice (blue) thickness showing significant ice and air loss. Elevation trends derived from satellite radar altimetry at the crossovers are cyan. Elevation and air thickness use the left axis, while TWTT and ice thickness are plotted with absolute values on the right axis and equivalent surface elevation on the left axis. (b) Spatial variation in ice mass budget. Divergence balances accumulation, and ice thinning is similar to unbalanced basal melting. Values in the legends represent means over all bins.

and air loss have different spatial patterns given their different (oceanic, ice-dynamic, and atmospheric) forcings.

\subsection{Ice and air budgets}

Figure 8 shows the maps of each term in the LCIS ice mass balance Eq. (9). Thinning along flow lines causes a sink of ice through divergence (Fig. 8a), advection is generally a source of ice where the ice shelf flows from thick to thin (Fig. 8b), and modelled surface accumulation is almost uniform (Fig. 8c). Their sum, the steady melting map (Fig. 8d), contains obvious artefacts but also many features that match our existing knowledge of ocean melting beneath LCIS. For example, the results are in agreement with a simple oceanlayer model (Holland et al., 2009) that predicts strong melting along the grounding line and freezing in the thinner ice immediately offshore of islands and peninsulas on the western coast (also visible as negative values in the advection term). A more sophisticated three-dimensional ocean model (Mueller et al., 2012), forced only by tides, predicts large values of tidally driven melting next to Bawden Ice Rise and Kenyon Peninsula, which also seem apparent in Fig. 8d, though other areas of high melting near the ice front and south of Kenyon Peninsula are not consistent with the model.

Combining the estimated mean terms in the ice mass budget (Fig. 8) with the ice loss derived along the survey line (Figs. 5a and 7a) allows us to consider the full unsteady ice budget (Figs. 5b and 7b). The basic ice balance is between accumulation and divergence, with advection becoming important at the southern end of the line. If the ice shelf were in steady state the derived oceanic melt rate would be an order of magnitude smaller than accumulation and divergence $\left(0.06 \mathrm{~m} \mathrm{yr}^{-1}\right)$. In fact, our derived ice loss profiles suggest a mean oceanic melt rate over the survey line of $0.26 \mathrm{~m} \mathrm{yr}^{-1}$, peaking at $0.5 \mathrm{~m} \mathrm{yr}^{-1}$ in the southernmost bin. These estimates are consistent with modelled patterns of melting (Holland et al., 2009; Mueller et al., 2012) and observations in a higher-melting region nearby (K. W. Nicholls, personal communication, 2014; Nicholls et al., 2012). Crucially, without basal melting the components of the mass budget are approximately balanced, so the majority of the melting is causing net ice loss. This emphasises that for ice shelves melted by cold ocean waters, relatively small absolute changes in melting can have a significant influence on the ice-shelf mass balance. In comparison, warm-water ice shelves such as Pine Island Glacier can have much larger melting perturbations (e.g. $5 \mathrm{~m} \mathrm{yr}^{-1}$; Wingham et al., 2009), causing correspondingly large thinning rates, but these perturbations are a much smaller fraction of the mean melt rate (e.g. $100 \mathrm{~m} \mathrm{yr}^{-1}$; Dutrieux et al., 2013).

The terms in the analogous firn-air budget are extremely uncertain. To put the derived air loss of $0.04 \mathrm{~m} \mathrm{yr}^{-1}$ into context, we simply note that there was $10-15 \mathrm{~m}$ of air in the surveyed section during the 1997/1998 survey (Holland et al., 2011), and if fresh snow is deposited at a density of $350-450 \mathrm{~kg} \mathrm{~m}^{-3}$ (Kuipers Munneke et al., 2012b) then the accumulation of $0.5 \mathrm{~m} \mathrm{yr}^{-1}$ ice implies the addition of $0.5-$ $1 \mathrm{~m} \mathrm{yr}^{-1}$ firn air each year before compaction is taken into account. Therefore, our best estimate is that the net air loss is only $5-10 \%$ of the annual air input.

\section{Error estimation}

The data contain a considerable amount of scatter and their interpretation relies upon a clear understanding of the uncer- 

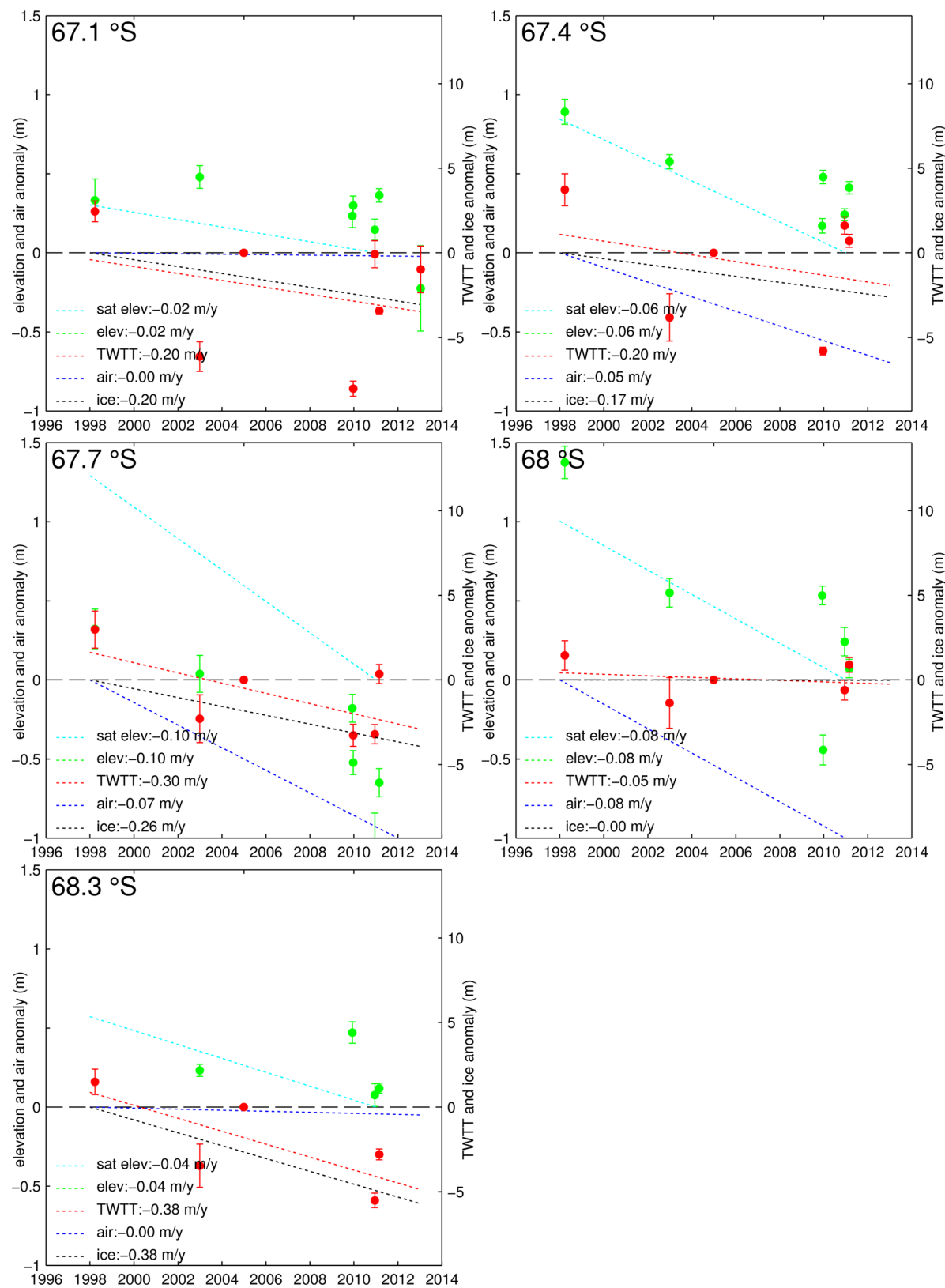

Figure 6. Data and trends for the five latitude bins defined by the satellite altimetry crossovers, labelled with the latitude of the accompanying crossover. Data points show the mean and $95 \%$ confidence intervals of the differences between each survey and the 2004 baseline for surface elevation (green) and TWTT (red, expressed as solid-ice equivalent). The satellite-altimeter-derived elevation trend for the crossover at the centre of each bin is also shown (cyan). Surveyed trends in elevation and TWTT are converted to trends in ice (black) and air (blue) thickness. Elevation and air thickness are plotted on the left-hand axis, while TWTT and ice thickness are plotted such that the right-hand axis shows absolute values and the left-hand axis shows the equivalent surface elevation.

tainties inherent in the derived trends. For this reason, we present a thorough error analysis before proceeding to discuss the implications of our findings. This analysis starts with a simple technique for visually assessing the reliability of the results before proceeding to more formal methods.

\subsection{Visual assessment}

It is possible to visually assess the reliability of ice and air trends from appropriately plotted trends in elevation and TWTT. If the TWTT trend is expressed as a solid-ice surfaceelevation equivalent, i.e. 

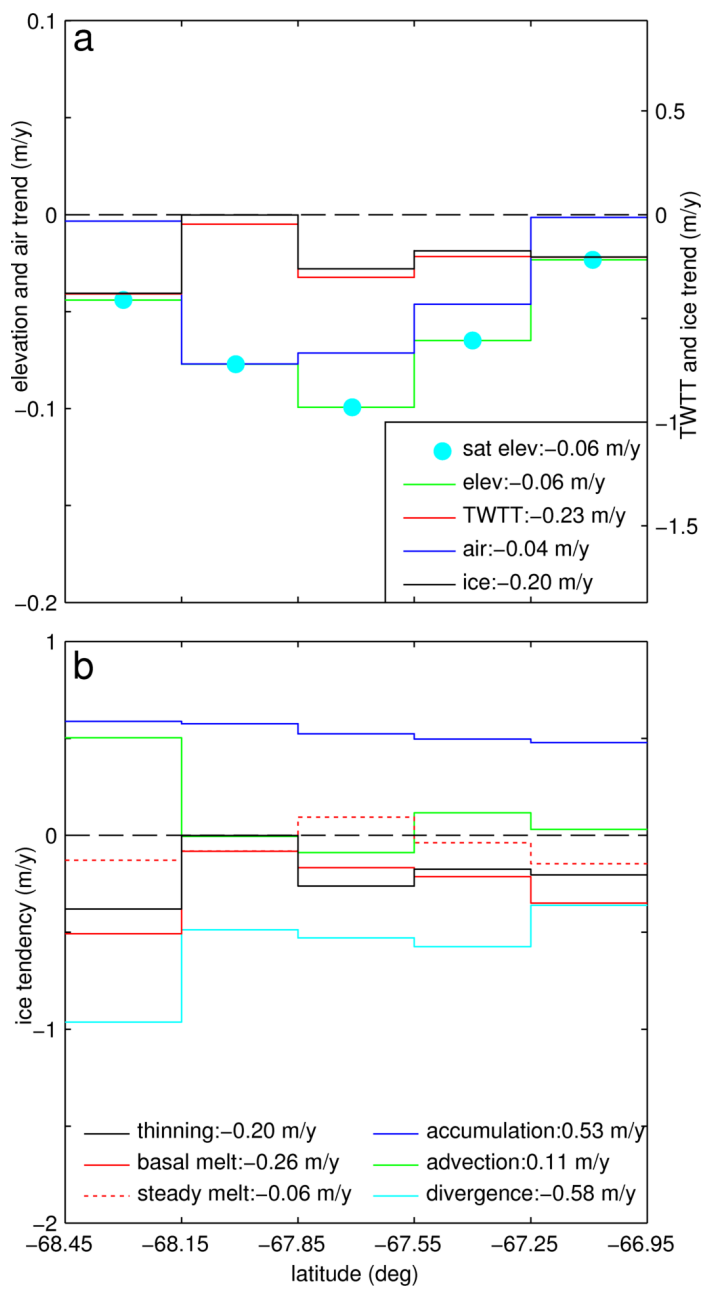

Figure 7. Version of Fig. 5 in which the binned survey elevation trends are replaced by satellite crossover elevation trends. (a) Spatial variation of trends in elevation (green), TWTT (red, ice equivalent), and air (black) and ice (blue) thickness. Satellite crossover trends are cyan. Elevation and air thickness use the left axis, while TWTT and ice thickness are plotted with absolute values on the right axis and equivalent surface elevation on the left axis. (b) Meridional variation in ice mass budget.

$$
\frac{\partial T_{\mathrm{s}}}{\partial t}=\frac{c}{2 n_{\mathrm{i}}} \frac{\rho_{\mathrm{o}}-\rho_{\mathrm{i}}}{\rho_{\mathrm{o}}-\rho_{\mathrm{A}}} \frac{\partial T}{\partial t},
$$

then comparing $\partial T_{\mathrm{s}} / \partial t$ to the elevation trend $\partial S / \partial t$ allows us to determine the value of $\partial A / \partial t$ from Eq. (5). Any elevation trend that is more negative than $\partial T_{\mathrm{s}} / \partial t$ implies a loss of air, with the air loss equal to 1.06 times the difference between $\partial S / \partial t$ and $\partial T_{\mathrm{s}} \partial t$. For this purpose, the two $y$ axes of Figs. 4, 5a, 6, and $7 \mathrm{a}$ are scaled such that the left-hand axis shows both ice surface elevation $(\partial S / \partial t)$ and TWTT expressed as solid-ice surface equivalent $\left(\partial T_{\mathrm{S}} / \partial t\right)$. Consideration of the numerator of Eq. (6) shows that $\partial T_{\mathrm{s}} / \partial t$ merely has to be more negative than $-0.107 \times \partial S / \partial t$ to imply a loss of ice; any $\partial T_{\mathrm{s}} / \partial t$ that is negative enough to be distinguished
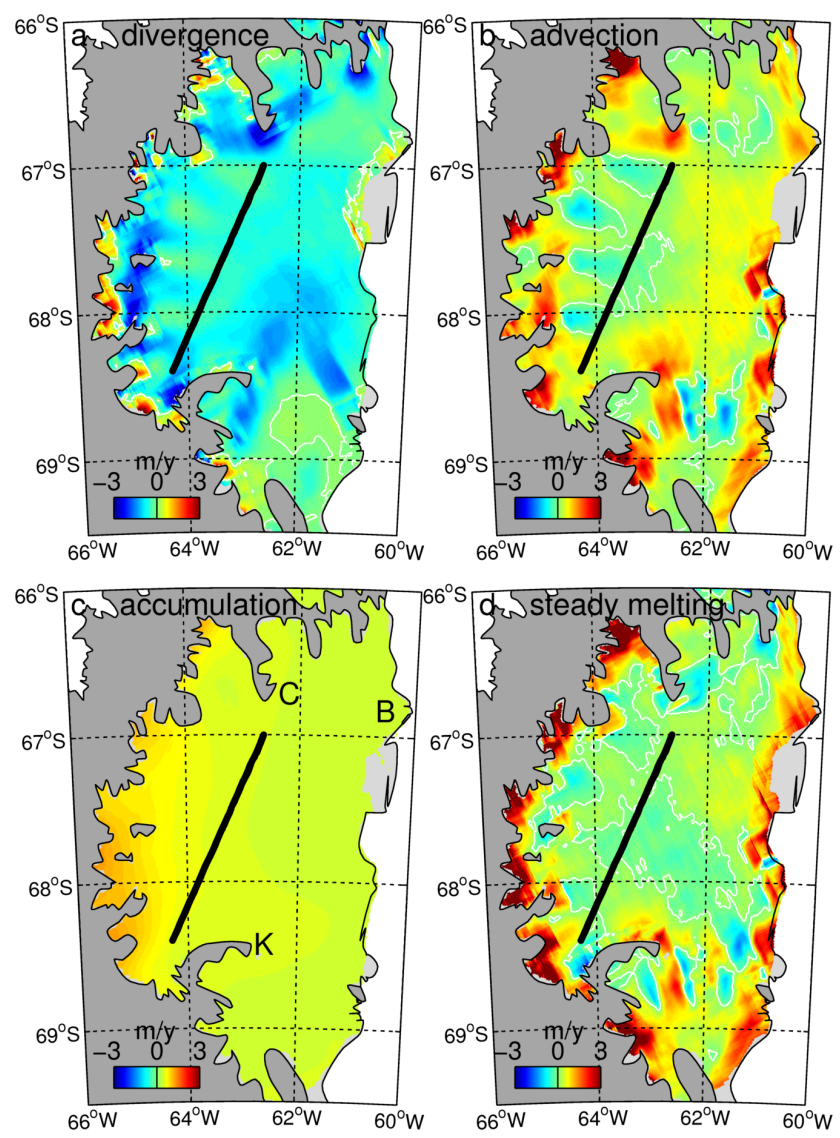

Figure 8. Fields of derived values for the terms in the ice-only mass balance (positive implies melting): (a) ice divergence $(-I \nabla \cdot u)$; (b) ice advection $(-\boldsymbol{u} \cdot \nabla I)$; (c) ice surface accumulation; (d) derived steady-state basal melting. (c) shows geographical features referred to in the text: B is Bawden Ice Rise; C is Churchill Peninsula; $\mathrm{K}$ is Kenyon Peninsula.

in the figures implies some ice loss. In plain terms, Fig. 4 is scaled such that if the red line (scaled TWTT trend) is parallel to the green line (elevation trend) then the lowering is due solely to ice loss, and if the red line is flat then all of the lowering is due to air loss.

These criteria allow a simple visual assessment of the signal present in the available data. Our assessment of Fig. 4 is that the scaled TWTT is decreasing but this result is not robust; that is, it is dependent upon all data sets and removing certain surveys would remove the calculated trend. This reduces confidence in the conclusion that ice loss has occurred. However, we do not believe that the scaled TWTT data could support a trend that is more negative than the elevation trend, and therefore we are confident in our conclusion that air loss has occurred.

A formal analysis revisits these conclusions below, but this requires many assumptions about the nature of the errors and so is not necessarily superior. There are many sources of error in our surveys, which we divide into two classes. The first 
Table 3. Statistics of the differences between data from each survey and their nearest 2004 analogue, as shown in Fig. 4. TWTT is expressed as solid-ice thickness equivalent.

\begin{tabular}{|c|c|c|c|c|c|c|c|c|}
\hline \multirow[t]{2}{*}{ Survey } & \multicolumn{4}{|c|}{ Elevation differences from 2004 (m) } & \multicolumn{4}{|c|}{ TWTT differences from 2004 (m ice) } \\
\hline & count & mean & SD & stderr & count & mean & SD & stderr \\
\hline 1998 & 2213 & 0.993 & 1.365 & 0.029 & 1382 & 2.320 & 7.507 & 0.202 \\
\hline 2002 & 5092 & 0.376 & 1.329 & 0.019 & 952 & -3.384 & 9.365 & 0.304 \\
\hline 2004 & 6097 & 0 & 0 & 0 & 18385 & 0 & 0 & 0 \\
\hline $2009 \mathrm{MG}$ & 8731 & -0.013 & 1.726 & 0.019 & 4385 & -5.441 & 9.501 & 0.144 \\
\hline $2009 \mathrm{IB}^{*}$ & 4779 & 0.215 & 1.139 & 0.017 & 4444 & -11.62 & 11.91 & 0.179 \\
\hline 2010 & 4461 & -0.088 & 1.836 & 0.028 & 5317 & -1.784 & 9.847 & 0.135 \\
\hline 2011 & 12126 & 0.020 & 1.573 & 0.014 & 9190 & -1.097 & 9.802 & 0.102 \\
\hline 2012 & 303 & -0.225 & 2.401 & 0.138 & 187 & -0.976 & 9.651 & 0.706 \\
\hline
\end{tabular}

* TWTT data neglected due to transmit/receive switch problem; see Sect. 2.3.

class of errors produces random intra-survey scatter, which affects the extent to which the data from each survey estimate the mean signal within that survey. The second class of errors creates a systematic signal across a whole survey, directly affecting inter-survey differences. The latter are of greatest concern because they have the largest effect on trends.

\subsection{Intra-survey errors}

Predominantly intra-survey errors include the following:

- instrument and processing error (including radar picking error, assumed intra-survey because all surveys were re-picked consistently)

- spatial offset from the 2004 survey reference line (there is no systematic spatial difference between surveys, but the data deviate from a straight line within surveys, and the mean east-west gradients in ice thickness and firn air thus induce intra-survey error)

- advection of complex ice topography through the survey line (assumed intra-survey because ice features are smaller than both the along-survey distance and the advection length scale in the across-survey direction: 15 years $\times 400 \mathrm{~m} \mathrm{yr}^{-1}$ ).

We can easily quantify these random errors by considering, for each survey, the statistics of each population of differences of data points from their 2004 analogues (Table 3). Standard deviations are relatively large, $1-2 \mathrm{~m}$ for elevation and $\sim 10 \mathrm{~m}$ ice equivalent for TWTT, as expected from previous analyses of the error in individual point measurements (Holland et al., 2009). However, when all data are considered the standard errors are small due to the large sample sizes. Assuming that the differences are independent and normally distributed, $95 \%$ confidence interval bounds for the survey mean are given by multiplying the standard error by 1.96 , as shown by the error bars in Fig. 4. We estimate overall $95 \%$ confidence interval bounds as $\pm 0.04 \mathrm{~m}$ for elevation and $\pm 0.5 \mathrm{~m}$ ice equivalent for TWTT. Thus, from a random error perspective, we are confident that all surveys differ significantly from 2004 apart from the elevation differences in the 2011 and McGrath 2009 surveys and both elevation and TWTT data sets in 2012. Simple examination of the error bars in Fig. 4 shows that variation within these random error bounds will have negligible effect on the computed trends.

\subsection{Inter-survey errors}

Predominantly inter-survey errors include the following:

- differences among survey instruments, calibration, and processing (radar altimeter penetration, ice-penetrating radar power and frequency, speed and altitude of acquisition platform)

- time-variable presence of liquid meltwater in the firn column

- time-variable firn penetration in the ice-penetrating radar surface pick

- the time-variable part of dynamic ocean topography (inter-survey because most surveys are rapid compared to the relevant variations in ocean flow; affects elevation only)

- error in the tidal model correction (inter-survey because most surveys are rapid compared to tides; affects elevation only)

- the inverse barometer effect (inter-survey because most surveys are rapid compared to the relevant variations in atmospheric pressure; affects elevation only).

An initial concern is that the NASA IceBridge and NASACECS surveys (high altitude, high speed, consistent radar systems, laser altimeter) differ from the BAS airborne surveys (lower altitude, slower, different radar, radar altimeter) and both differ from the ground-based surveys (lowfrequency radar, GPS elevation). However, the three types 
of survey are interleaved in time, so such differences do not necessarily cause systematic trends. The issue is assessed by re-calculating the trends using different combinations of data (Table 2). Considering only the two BAS surveys produces broadly the same results. However, considering only NASA IceBridge and NASA-CECS surveys produces a much weaker surface lowering and no decrease in TWTT, so that the ice loss disappears. Systematically removing the surveys from the calculation reveals that it is neglecting the BAS 1998 survey that removes these trends. We know of no reason to neglect this survey, but this suggests that we treat TWTT and ice trends with additional caution.

The presence of meltwater in the firn would require us to adapt the methodology because it affects both the hydrostatic floatation and radar-wave delay of the ice shelf, as described by Holland et al. (2011), leading to different ice and air thicknesses being derived from the same TWTT and elevation. This potentially confounding issue is neglected because most surveys were sampled in November, before the onset of melt (Barrand et al., 2013), and instrumented boreholes have revealed no evidence of a perennial aquifer (K. W. Nicholls and B. Hubbard, personal communications, 2015). However, the two BAS surveys were sampled in summer and could be contaminated by the presence of meltwater. Repeating the derivation of Eqs. (3) and (4) but including the effects of meltwater produces new equations from which $0.57 \mathrm{~m}$ more air and $5.6 \mathrm{~m}$ less ice would be derived for every $1 \mathrm{~m}$ of meltwater present (Holland et al., 2011). A maximum LCIS meltwater content of $0.4 \mathrm{~m}$ (Holland et al., 2011) therefore implies a maximum underestimate of $0.23 \mathrm{~m}$ air and overestimate of $2.24 \mathrm{~m}$ ice. The summer of 1997/1998 was a high melting year (Tedesco, 2009), and if meltwater was present during the 1998 survey the derived air content should be higher and ice content lower, enhancing the air loss trend and reducing the ice loss trend. A linear regression to $0.23 \mathrm{~m}$ air error and $-2.24 \mathrm{~m}$ ice error in 1998 and no meltwaterderived error in the other surveys yields maximum trend errors of $-0.0137 \mathrm{~m} \mathrm{yr}^{-1}$ air and $+0.134 \mathrm{~m} \mathrm{yr}^{-1}$ ice. Melt estimates for 2010/2011 are not available, but any 2011 meltwater would have the opposite effect on the inter-survey trends to 1998 meltwater and thus mitigate this issue.

For the airborne surveys, surface penetration could affect both radar altimeters and the surface pick of ice-penetrating radars. We have used a penetration correction in radar altimeter data (see above), and their agreement with the satellite elevation trend implies that deviation from this correction is not important. Our strategy of finding the ice TWTT by picking the surface and basal returns and differencing the result means that surface penetration could affect the TWTT. We examine this by comparing the radar surface picks with altimeter data. This test is imperfect because it introduces error from the aircraft altitude and surface elevation data and requires absolute accuracy in the radar data that is not needed of the TWTT differences used. The test cannot even be performed for the NASA IceBridge and NASA-CECS surveys because the absolute timing of the radar pulse transmission is not known to the required accuracy. The mean difference between altimeter-derived surface elevations and radar-derived surface elevations is $2.14 \mathrm{~m}$ for the BAS 1998 survey and $2.38 \mathrm{~m}$ for the BAS 2011 survey. The altimeter-derived elevation is higher than the radar-derived elevation in both cases, so the difference may be caused by surface penetration. This very limited data set suggests that radar firn penetration is of the order of $2 \mathrm{~m}$, with an interannual variability of order $0.2 \mathrm{~m}$.

These differences between radar surface picks and altimeter data are also the only independent information we have to quantify overall inter-survey error in TWTT differences. They are again imperfect in this role because they include errors in aircraft altitude and surface elevation data that does not appear in the TWTT differences used in Eqs. (5) and (6). Also, if the error in basal and surface picks is identical (e.g. from an absolute calibration error) then there is no error in their difference. However, if the surface and basal errors are uncorrelated and of the same magnitude then the TWTT difference error is the surface pick error multiplied by $\sqrt{2}$. We believe that an inter-survey error of $2 \mathrm{~m}$ ice equivalent for TWTT is a reasonable compromise, and this value is in good agreement with the deviation of the TWTT points from the trend line in Fig. 4.

The effects of unsteady dynamic ocean topography, error in the tidal correction, and inverse barometer effect should each contribute an inter-survey error of the order of $0.1 \mathrm{~m}$ to the surface elevation differences (L. Padman, personal communication, 2014; Padman et al., 2003; King and Padman, 2005). If these errors are uncorrelated, this would create a total error of about $0.2 \mathrm{~m}$, and this estimate is consistent with both the deviation of the surveys from the linear trend and the difference in elevation between the two 2009 surveys (Fig. 4). In any case, the surface lowering from the satellite crossovers provides an independent test of the surveyed elevation trend, and the two trends are only slightly different (Table 2) as might be expected from the difference in spatial and temporal sampling.

Given these overall inter-survey error estimates $(0.2 \mathrm{~m}$ elevation and $2 \mathrm{~m}$ TWTT ice equivalent), we used a Monte Carlo approach to estimate the resultant uncertainty in the elevation and TWTT trends. The trends were recalculated 500000 times with all data points subject to a perturbation drawn from a normal distribution with $95 \%$ confidence interval bounds equal to the error estimates. This yields a population of trends with $95 \%$ confidence interval bounds of $\pm 0.017 \mathrm{~m} \mathrm{yr}^{-1}$ for elevation trends and $\pm 0.17 \mathrm{~m} \mathrm{yr}^{-1}$ ice equivalent for TWTT trends. Evaluating the terms as in Eqs. (7) and (8) and combining the errors in quadrature yields

$$
\begin{aligned}
& \varepsilon_{A t}=\sqrt{0.013 \varepsilon_{T t}^{2}+1.13 \varepsilon_{S t}^{2}}, \\
& \varepsilon_{I t}=\sqrt{1.13 \varepsilon_{T t}^{2}+0.36 \varepsilon_{S t}^{2}},
\end{aligned}
$$


where $\varepsilon_{A t}, \varepsilon_{I t}$, and $\varepsilon_{S t}$ are errors in $\partial A / \partial t, \partial I / \partial t$, and $\partial S / \partial t$ respectively. The symbol $\varepsilon_{T t}$ represents the error in $c / 2 n_{\mathrm{i}} \partial T / \partial t$, TWTT converted to solid ice thickness. These formulae yield uncertainties of $\pm 0.026 \mathrm{~m} \mathrm{yr}^{-1}$ for $\partial A / \partial t$ and $\pm 0.18 \mathrm{~m} \mathrm{yr}^{-1}$ for $\partial I / \partial t$.

\subsection{Error summary}

In summary, formal error estimates suggest that both the ice and air loss derived in our reference calculation are robust. However, visual assessment of Fig. 4 suggests that the data support air loss more strongly than ice loss. Recalculating the trends with different combinations of the data (Table 2) shows that almost all possible calculations have significant air loss; the only way to obtain insignificant air loss is to include 2009 IceBridge TWTT data known to be erroneous. However, removing either the BAS 1998 or McGrath 2009 surveys is sufficient to render the ice loss insignificant. Any meltwater that was present during the BAS 1998 survey would further strengthen the air loss and weaken the ice loss. Our best estimate is that the lowering is a result of both air loss and ice loss, but there remains a possibility that air loss is solely responsible.

The preceding calculations apply to the whole-survey comparisons shown in Fig. 4. The latitude bins shown in Figs. 5-7 contain fewer data, so the intra-survey standard error should increase. Standard errors scale with the reciprocal square root of the number of data points, so the $95 \%$ confidence interval bounds approximately double $( \pm 0.08 \mathrm{~m}$ for elevation and $\pm 1 \mathrm{~m}$ ice equivalent for TWTT) when the data sample size is reduced by a factor of 5 . Inter-survey systematic error should in principle remain similar, but on the shorter length scale of an individual bin, several intra-survey errors become inter-survey in character (differences in radar picking, survey path, and advection of ice features, which can be a significant fraction of a bin length in the along-survey direction). Scrutinising the time series in Fig. 6 suggests a reasonable confidence in the binned trends. In most cases a downward trend of the TWTT is apparent, suggesting some ice loss has occurred, and the scaled TWTT data would not support a downwards trend steeper than the satellite elevation, suggesting air loss has occurred. The steepest elevation trends and shallowest TWTT trends are in the centre of the survey line, implying greatest air loss.

\section{Discussion}

The uncertainties are considerable, but our primary estimate is that the lowering $\left(0.066 \pm 0.017 \mathrm{~m} \mathrm{yr}^{-1}\right.$, or $\left.0.99 \pm 0.26 \mathrm{~m}\right)$ is caused by both ice loss $\left(0.28 \pm 0.18 \mathrm{myr}^{-1}\right.$, or $4.2 \pm 2.7 \mathrm{~m})$ and firn-air loss $\left(0.037 \pm 0.026 \mathrm{~m} \mathrm{yr}^{-1}\right.$, or $0.56 \pm 0.39 \mathrm{~m}$ ). It is notable that though their effect on the lowering is approximately equal, ice loss is an order of magnitude larger than air loss. The derivation of these values al- lows us to speculate upon the possible sources of the changes and their future implications.

\subsection{Sources of change}

The existence of mean rates of change in ice and air over our 15-year period implies an imbalance in the other terms of Eqs. (9) and (10) during this time. We consider the ability of each of these terms to cause the imbalance and therefore the ice and air losses. Whether the budget was ever balanced in the past, with the observed imbalance then implying that changes have occurred, is a separate question that we cannot answer.

We start with sources and sinks. Above-balance basal melting will cause ice loss but not air loss and can easily account for our ice loss signal. Any melting greater than a few centimetres per year can cause an imbalance (Fig. 7), and observations and models easily support the rates of $\sim 0.26 \mathrm{~m} \mathrm{yr}^{-1}$ needed to explain the ice loss (Holland et al., 2009; Mueller et al., 2012; Nicholls et al., 2012). Abovebalance surface melting and refreezing or dry compaction will cause only air loss, and it is again easy for these processes to account for the air loss signal observed here. Belowbalance surface accumulation will cause air and ice loss at a ratio of $2: 1-1: 1$ if snow is initially deposited at a density of $350-450 \mathrm{~kg} \mathrm{~m}^{-3}$ (Kuipers Munneke et al., 2012b) and compensating compaction changes are ignored. Below-balance accumulation of approximately half of the modelled value (Fig. 7b) would be required to solely explain our ice loss; the fact that our ice loss is an order of magnitude larger than the air loss suggests that below-balance accumulation alone cannot account for both. A small below-balance accumulation could, however, explain the air loss. Since the total input of air into the firn is $0.5-1 \mathrm{~m} \mathrm{yr}^{-1}$, relatively small anomalies in surface melting, dry compaction, or accumulation are required to yield the observed $0.04 \mathrm{~m} \mathrm{yr}^{-1}$ air loss.

We now turn to dynamic mechanisms. Above-balance ice flow advection will affect air and ice thicknesses in proportion to their relative gradients along flow. According to the results of Holland et al. (2011), increased advection would enhance the flow of thicker ice with less firn air across the survey line. The air thickness increases along flow by approximately $1 \mathrm{~m}$ for every $10 \mathrm{~m}$ decrease in along-flow ice thickness. Above-balance advection would therefore cause air loss but accompanied by ice gain approximately 10 times faster, which entirely contradicts our observed signals. Abovebalance ice flow divergence will cause air and ice losses in proportion to their relative thicknesses, approximately $1: 30$ for characteristic ice and air thicknesses of 10 and $300 \mathrm{~m}$. The largest velocity change in the literature is an acceleration of $80 \mathrm{~m} \mathrm{yr}^{-1}$ between 2000 and 2006 surveys of northern LCIS (Haug et al., 2010; Khazendar et al., 2011). If this acceleration caused unbalanced divergence over a length scale of $100 \mathrm{~km}$, it would cause ice loss of $\sim 0.24 \mathrm{~m} \mathrm{yr}^{-1}$ and air loss of $\sim 0.008 \mathrm{~m} \mathrm{yr}^{-1}$. Above-balance divergence could explain 
the ice loss, but not the air loss, if maintained at this level and not accompanied by above-balance advection.

In summary, the ice loss we observe could be explained by above-balance basal melting and/or ice divergence, and the air loss could be explained by below-balance accumulation and/or above-balance surface melting and/or compaction. Our results therefore suggest that at least two different forcings caused the lowering of LCIS during our survey period. Elsewhere around Antarctica, rapid ice-shelf thinning is thought to be driven by unbalanced ocean melting (e.g. Shepherd et al., 2004; Holland et al., 2010; Padman et al., 2012; Khazendar et al., 2013), and our robust evidence of a firn-air loss from LCIS in response to surface processes is the first direct evidence of an exception to this. The existence of at least two different mechanisms underlying the change is also consistent with our observation that the ice and air loss signals have different spatial variation along the survey line.

The surveys do not encompass all of the known ice-shelf lowering (Fig. 1), and it is likely that the balance of ice and air losses, and their driving mechanisms, varies in different regions and periods. In particular, our surveys do not capture the rapid lowering in northern LCIS. Ice divergence may play a part in this, since the known acceleration of LCIS is northward-intensified (Haug et al., 2010; Khazendar et al., 2011), but there are also good reasons to expect changes in surface melting to be largest in the north (Holland et al., 2011; Trusel et al., 2013; Luckman et al., 2014). The pattern of changes in basal melting is unknown.

\subsection{Ice-shelf stability}

Our results have important implications for the future stability of LCIS and thus the AP Ice Sheet. Previous iceshelf collapses are thought to have been accomplished by surface meltwater-driven crevassing (van der Veen, 1998; Scambos et al., 2003; van den Broeke, 2005; Banwell et al., 2013) and ice-front retreat past a "compressive arch" in strain rates (Doake et al., 1998; Kulessa et al., 2014). We conceive several interconnected mechanisms by which LCIS stability could be compromised: (1) ice-front retreats past a compressive arch; (2) increased surface melting causes firn depletion and meltwater-driven crevassing; (3) decreased ocean freezing or increased melting depletes marine ice, permitting the propagation of crevasses; (4) collapse of the remnant LBIS opens a new ice front at the northern margin of LCIS; (5) ungrounding from Bawden Ice Rise removes an ice-front pinning point; (6) ice thinning and acceleration enhances the propagation of crevasses and weakens shear zones.

\subsubsection{Retreat past compressive arch}

Doake et al. (1998) suggested that LBIS was stable when the second principal strain rate was compressive inshore of a "compressive arch" near the ice front. Once this arch was breached by calving, a significant collapse followed. Kulessa et al. (2014) showed that LCIS has a large region in which the second principal stress is tensile and thus offshore of a compressive arch. Kulessa et al. (2014) also considered the angle between the flow and first principal stress under the assumption that rifts strike perpendicular to flow, arguing that a first principal stress aligned with the flow would tend to open rifts, rendering the ice shelf unstable. LCIS has a large region with first principal stress across flow, stabilising the ice shelf according to this measure. This region is secured by marine ice, but there is clearly a risk that calving will remove ice that stabilises rifts and shields the compressive arch, leading to progressive collapse of LCIS. Worryingly, a rift in the south of LCIS has propagated rapidly beyond a band of marine ice that has stabilised all such rifts during the observational era (Jansen et al., 2015). Depending upon its evolution, this rift may threaten the LCIS compressive arch within a few years.

\subsubsection{Meltwater-driven crevassing}

The collapse of many AP ice shelves has been linked to the availability of surface meltwater to enhance the downward propagation of surface crevasses (Scambos et al., 2003; van den Broeke, 2005; Banwell et al., 2013). There are significant crevasse fields on LCIS, so we hypothesise that future increases in meltwater ponding could contribute to ice-shelf collapse. Currently, meltwater ponds form in limited areas near the LCIS grounding line (Holland et al., 2011; Luckman et al., 2014), but these do not pose an imminent risk of collapse. Before more extensive ponding can occur it is necessary for the firn to be depleted of its air content, since otherwise meltwater will simply percolate and refreeze. Holland et al. (2011) showed that northern LCIS had approximately 10 m of firn air in 1998, while the retreating LBIS had very little. Our derived air loss of $0.04 \mathrm{~m} \mathrm{yr}^{-1}$ would require 250 years to deplete $10 \mathrm{~m}$ of air and threaten LCIS stability. However, the lowest air content and highest lowering are north of the survey line, and it is likely that surface melting will increase over the coming centuries (Kuipers Munneke et al., 2014), so this timescale is probably an upper bound.

\subsubsection{Depletion of marine ice}

LCIS is stabilised by marine ice (Holland et al., 2009; Khazendar et al., 2011; Jansen et al., 2013; Kulessa et al., 2014; McGrath et al., 2014), so decreased marine ice deposition or increased melting could allow LCIS to collapse under its existing strain field. Marine ice at the ice front can form a very small fraction of the ice column, implying that the stability of basal crevassing and calving is controlled by only tens of metres of marine ice (McGrath et al., 2014). Elsewhere the marine ice can be hundreds of metres thick (Jansen et al., 2013; Kulessa et al., 2014; McGrath et al., 2014). If our ice loss of $0.3 \mathrm{~m} \mathrm{yr}^{-1}$ is caused by unbalanced basal melting, this suggests a timescale of 170 years to remove the bottom 
$50 \mathrm{~m}$ of ice, destabilising the ice front, and 500 years to remove $150 \mathrm{~m}$ of ice, destabilising the eastern half of LCIS. These timescales are extremely uncertain because the ocean processes driving melting and freezing are unknown and impossible to project. If marine ice deposition were to cease altogether, it would take $400-500$ years to remove the existing marine ice from LCIS by lateral ice advection and iceberg calving.

\subsubsection{Collapse of remnant LBIS}

Albrecht and Levermann (2014) propose that an ice-shelf collapse can destabilise neighbouring ice shelves by changing their stress regime. For LCIS, this translates into the risk that a LBIS collapse removes buttressing by ungrounding ice along Jason Peninsula. When the majority of LBIS collapsed in 2002, a remnant ice shelf was left immediately adjacent to LCIS (Fig. 9a). This ice is accelerating and apparently weakening (Khazendar et al., 2015), so we consider the impact upon LCIS of its potential removal. Jason Peninsula anchors a large area of stagnant ice that is a significant stabilising influence on both LCIS and the remnant LBIS (Fig. 9a). The ice dividing LCIS and LBIS, Philippi Rise, is poorly surveyed but appears to be well grounded at present at $150 \mathrm{~m}$ above floatation (calculated using $5 \mathrm{~m}$ firn air from Holland et al. (2011), EIGEN-6C geoid, and mean dynamic ocean topography of $-1 \mathrm{~m}$; Fig. 9b). However, the ice base is hundreds of metres below sea level (Fig. 9c), so if the remnant LBIS were to collapse it is possible that subsequent ice thinning could unground Philippi Rise, removing buttressing from LCIS and opening a new oceanographic pathway. The timescale for such a possibility is impossible to predict and, given the stagnant nature of this ice, it is unclear to what extent this would influence LCIS stability.

\subsubsection{Ungrounding from Bawden Ice Rise}

An ungrounding from Bawden Ice Rise would prompt significant acceleration of LCIS (Borstad et al., 2013) and reorganisation of its strain field, probably destabilising the ice front (Kulessa et al., 2014). Bawden is only a few kilometres across but has a significant effect upon the flow and structure of the ice shelf (Fig. 10a). Three radar survey lines show that Bawden is very lightly grounded in the north but approximately $40 \mathrm{~m}$ above floatation at its summit in the south (Fig. 10b), where the ice base is about $150 \mathrm{~m}$ below sea level (Fig. 10c) (height above floatation is calculated using a $10 \mathrm{~m}$ firn-air content derived from nearby surveyed floating ice and finding elevation relative to sea level using nearby surveyed open water). Our ice loss estimate of $0.3 \mathrm{~m} \mathrm{yr}^{-1}$ would take 130 years to unground Bawden entirely, but this timescale is subject to great uncertainty, including the ice loss estimate itself, its applicability to this region, and its projection into the future. It is almost certainly an upper bound because lowering is rapid in the region (Fig. 1) and Bawden would

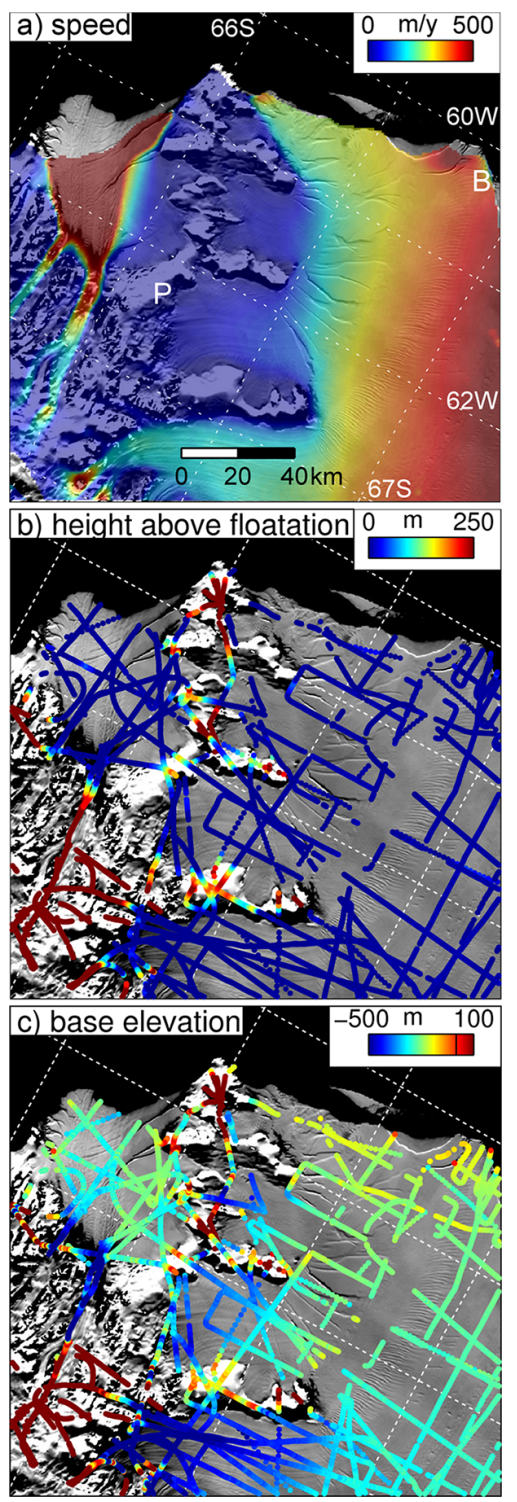

Figure 9. Northern LCIS and Jason Peninsula, showing various quantities overlain on MODIS Mosaic of Antarctica (Scambos et al., 2007): (a) ice flow speed (Rignot et al., 2011); (b) height of ice surface above hydrostatic floatation; (c) elevation of ice base relative to sea level. Bawden Ice Rise is labelled B and Philippi Rise is labelled P.

cease to provide a significant stabilising influence, and may even destabilise the ice front, long before the ice ungrounds through thinning. For example, Doake and Vaughan (1991) showed that ice rises acted as an "indenting wedge" during the retreat of Wordie Ice Shelf. A large calving occurred south of Bawden between late December 2004 and early January 2005, and the ongoing thinning (Paolo et al., 2015) and acceleration (Khazendar et al., 2011) in this region could indicate that ungrounding from Bawden is underway. 

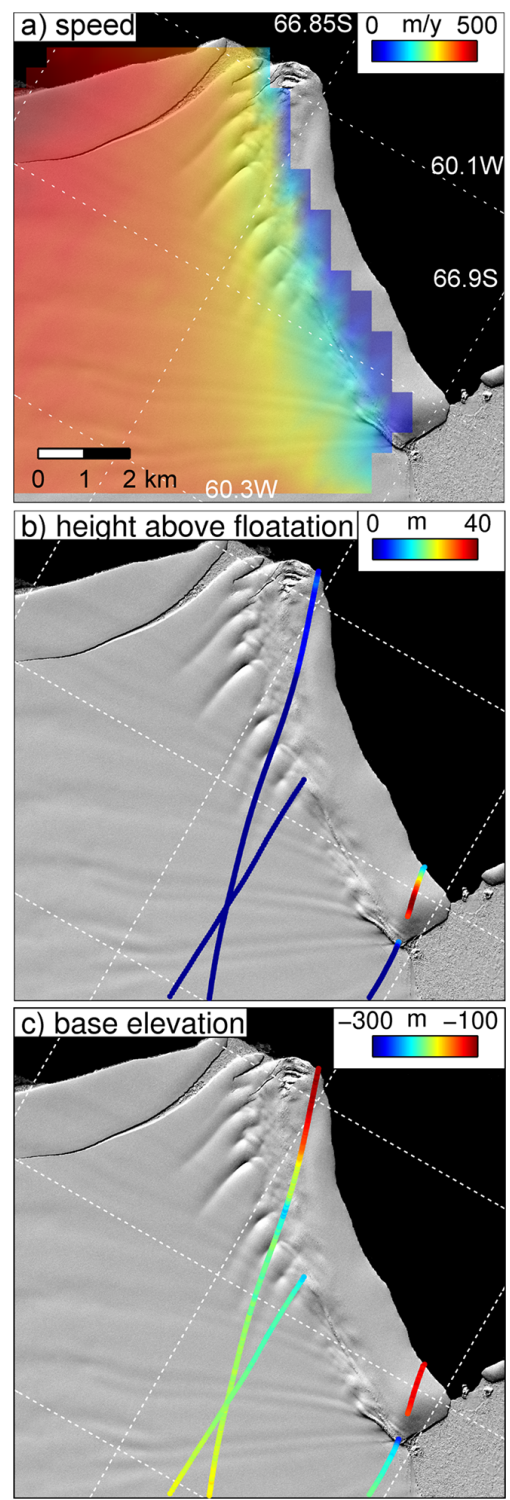

Figure 10. High-resolution WorldView2 satellite imagery of Bawden Ice Rise acquired 15 October 2012 (copyright Digital Globe) with various quantities overlain: (a) ice flow speed (Rignot et al., 2011); (b) height of ice surface above hydrostatic floatation; (c) elevation of ice base relative to sea level.

\subsubsection{Crevassing weakens shear zones}

Whatever its source, thinning and acceleration of LCIS could ultimately cause its demise by weakening the structural integrity of the ice shelf. LAIS and LBIS both accelerated before collapsing (Bindschadler et al., 1994; Rignot et al., 2004), and LBIS apparently collapsed after weakening of the shear zones between ice flow units (Khazendar et al., 2007; Vieli et al., 2007; Glasser and Scambos, 2008). The shear zones in LCIS are less strongly sheared (Khazendar et al., 2011) and hence more stable, but the ice is already quite damaged (Jansen et al., 2010; McGrath et al., 2012; Borstad et al.,
2013). The uncertainties in this interaction are large and we are unable to assess a timescale for this risk.

\section{Conclusions}

We analyse eight repeated radar surveys between 1998 and 2012 along a nearly meridional line that traverses the centre of Larsen C Ice Shelf, applying a novel method to derive the separate ice and air losses along this line contributing to the known lowering of the ice shelf. The uncertainties are considerable, but our primary estimate is that the lowering $\left(0.066 \pm 0.017 \mathrm{~m} \mathrm{yr}^{-1}\right.$, or $\left.0.99 \pm 0.26 \mathrm{~m}\right)$ is caused by both ice loss $\left(0.28 \pm 0.18 \mathrm{~m} \mathrm{yr}^{-1}\right.$, or $\left.4.2 \pm 2.7 \mathrm{~m}\right)$ and firn-air loss $\left(0.037 \pm 0.026 \mathrm{~m} \mathrm{yr}^{-1}\right.$, or $\left.0.56 \pm 0.39 \mathrm{~m}\right)$. Though their effect on the surface lowering is approximately equal because the ice is floating, ice loss is an order of magnitude larger than air loss and so the results suggest that ice loss is the dominant change affecting LCIS. The derivation of these values allows us to speculate the possible sources of the changes and their future implications.

The ice loss we observe could be explained by abovebalance basal melting and/or ice divergence, and the air loss could be explained by below-balance accumulation and/or above-balance surface melting and/or compaction. We conclude that at least two different forcings caused the lowering of LCIS during our survey period. The surveys do not sample the most rapid ice-shelf lowering in northern LCIS and it is likely that the balance of ice and air losses, and their driving mechanisms, varies for different regions and periods.

We conceive several interconnected mechanisms by which LCIS stability could be compromised. The two mechanisms that offer the earliest possibility of collapse are a flow perturbation arising from the ungrounding of LCIS from Bawden Ice Rise and ice-front retreat past a "compressive arch" in strain rates. Ice lowering is now focussed around Bawden Ice Rise (Paolo et al., 2015), and the anomalous propagation of a rift in the south of LCIS may threaten the compressive arch (Jansen et al., 2015), suggesting that either mechanism could pose an imminent risk and both should be monitored closely.

Acknowledgements. We gratefully acknowledge the vital contribution of many dedicated field workers and support staff in enabling the radar and satellite campaigns underpinning this study. The imagery in Fig. 10 was provided by the Polar Geospatial Center at the University of Minnesota under NSF OPP agreement ANT-1043681. Laurie Padman is gratefully acknowledged for providing the satellite radar altimetry data and much useful advice.

Edited by: O. Gagliardini 


\section{References}

Albrecht, T. and Levermann, A.: Spontaneous ice-front retreat caused by disintegration of adjacent ice shelf in Antarctica, Earth Planet. Sc. Lett., 393, 26-30, doi:10.1016/j.eps1.2014.02.034, 2014.

Arcone, S. A.: Airborne-radar stratigraphy and electrical structure of temperate firn: Bagley Ice Field, Alaska, USA, J. Glaciol., 48, 317-334, doi:10.3189/172756502781831412, 2002.

Banwell, A. F., MacAyeal, D., and Sergienko, O. V.: Breakup of the Larsen B Ice Shelf triggered by chain reaction drainage of supraglacial lakes, Geophys. Res. Lett., 40, 5872-5876, doi:10.1002/2013GL057694, 2013.

Barrand, N. E., Vaughan, D. G., Steiner, N., Tedesco, M., Munneke, P. K., van den Broeke, M. R., and Hosking, J. S.: Trends in Antarctic Peninsula surface melting conditions from observations and regional climate modeling, J. Geophys. Res.-Earth, 118, 315-330, doi:10.1029/2012jf002559, 2013.

Bathmann, U., Smetacek, V., de Baar, H., Fahrbach, E., and Krause, G.: The expeditions ANTARKTIS X/6-8 of the research vessel "POLARSTERN" in 1992/93, Alfred-Wegener-Institut, Bremerhaven, Germany, 236 pp., 1994.

Berthier, E., Scambos, T. A., and Shuman, C. A.: Mass loss of Larsen B tributary glaciers (Antarctic Peninsula) unabated since 2002, Geophys. Res. Lett., 39, L13501, doi:10.1029/2012g1051755, 2012.

Bindschadler, R. A., Fahnestock, M. A., Skvarca, P., and Scambos, T. A.: Surface-Velocity Field of the Northern Larsen Ice Shelf, Antarctica, Ann. Glaciol., 20, 319-326, doi:10.3189/172756494794587294, 1994.

Borstad, C. P., Rignot, E., Mouginot, J., and Schodlok, M. P.: Creep deformation and buttressing capacity of damaged ice shelves: theory and application to Larsen $\mathrm{C}$ ice shelf, The Cryosphere, 7, 1931-1947, doi:10.5194/tc-7-1931-2013, 2013.

Brisbourne, A. M., Smith, A. M., King, E. C., Nicholls, K. W., Holland, P. R., and Makinson, K.: Seabed topography beneath Larsen C Ice Shelf from seismic soundings, The Cryosphere, 8, 1-13, doi:10.5194/tc-8-1-2014, 2014.

Cook, A. J. and Vaughan, D. G.: Overview of areal changes of the ice shelves on the Antarctic Peninsula over the past 50 years, The Cryosphere, 4, 77-98, doi:10.5194/Tc-4-77-2010, 2010.

Doake, C. S. M. and Vaughan, D. G.: Rapid Disintegration of the Wordie Ice Shelf in Response to Atmospheric Warming, Nature, 350, 328-330, doi:10.1038/350328a0, 1991.

Doake, C. S. M., Corr, H. F. J., Rott, H., Skvarca, P., and Young, N. W.: Breakup and conditions for stability of the northern Larsen Ice Shelf, Antarctica, Nature, 391, 778-780, doi:10.1038/35832, 1998.

Domack, E., Duran, D., Leventer, A., Ishman, S., Doane, S., McCallum, S., Amblas, D., Ring, J., Gilbert, R., and Prentice, M.: Stability of the Larsen B ice shelf on the Antarctic Peninsula during the Holocene epoch, Nature, 436, 681-685, doi:10.1038/Nature03908, 2005.

Dutrieux, P., Vaughan, D. G., Corr, H. F. J., Jenkins, A., Holland, P. R., Joughin, I., and Fleming, A. H.: Pine Island glacier ice shelf melt distributed at kilometre scales, The Cryosphere, 7, 15431555, doi:10.5194/tc-7-1543-2013, 2013.

Fricker, H. A. and Padman, L.: Thirty years of elevation change on Antarctic Peninsula ice shelves from multimission satel- lite radar altimetry, J. Geophys. Res.-Oceans, 117, C02026, doi:10.1029/2011jc007126, 2012.

Glasser, N. F. and Scambos, T. A.: A structural glaciological analysis of the 2002 Larsen B ice-shelf collapse, J. Glaciol., 54, 3-16, doi:10.3189/002214308784409017, 2008.

Griggs, J. A. and Bamber, J. L.: Ice shelf thickness over Larsen C, Antarctica, derived from satellite altimetry, Geophys. Res. Lett., 36, L19501, doi:10.1029/2009g1039527, 2009.

Haug, T., Kaab, A., and Skvarca, P.: Monitoring ice shelf velocities from repeat MODIS and Landsat data - a method study on the Larsen C ice shelf, Antarctic Peninsula, and 10 other ice shelves around Antarctica, The Cryosphere, 4, 161-178, doi:10.5194/tc4-161-2010, 2010.

Hellmer, H. H., Huhn, O., Gomis, D., and Timmermann, R.: On the freshening of the northwestern Weddell Sea continental shelf, Ocean Science, 7, 305-316, doi:10.5194/os-7-305-2011, 2011.

Holland, P. R., Corr, H. F. J., Vaughan, D. G., Jenkins, A., and Skvarca, P.: Marine ice in Larsen Ice Shelf, Geophys. Res. Lett., 36, L11604, doi:10.1029/2009g1038162, 2009.

Holland, P. R., Jenkins, A., and Holland, D. M.: Ice and ocean processes in the Bellingshausen Sea, Antarctica, J. Geophys. Res.Oceans, 115, C05020, doi:10.1029/2008jc005219, 2010.

Holland, P. R., Corr, H. F. J., Pritchard, H. D., Vaughan, D. G., Arthern, R. J., Jenkins, A., and Tedesco, M.: The air content of Larsen Ice Shelf, Geophys. Res. Lett., 38, L10503, doi:10.1029/2011g1047245, 2011.

Jansen, D., Kulessa, B., Sammonds, P. R., Luckman, A., King, E. C., and Glasser, N. F.: Present stability of the Larsen C ice shelf, Antarctic Peninsula, J. Glaciol., 56, 593-600, doi:10.3189/002214310793146223, 2010.

Jansen, D., Luckman, A., Kulessa, B., Holland, P. R., and King, E. C.: Marine ice formation in a suture zone on the Larsen C Ice Shelf and its influence on ice shelf dynamics, J. Geophys. Res.Earth, 118, 1628-1640, doi:10.1002/Jgrf.20120, 2013.

Jansen, D., Luckman, A. J., Cook, A., Bevan, S., Kulessa, B., Hubbard, B., and Holland, P. R.: Brief Communication: Newly developing rift in Larsen $C$ Ice Shelf presents significant risk to stability, The Cryosphere Discuss., 9, 861-872, doi:10.5194/tcd9-861-2015, 2015.

Jullion, L., Garabato, A. C. N., Meredith, M. P., Holland, P. R., Courtois, P., and King, B. A.: Decadal Freshening of the Antarctic Bottom Water Exported from the Weddell Sea, J. Climate, 26, 8111-8125, doi:10.1175/Jcli-D-12-00765.1, 2013.

Khazendar, A., Rignot, E., and Larour, E.: Larsen B Ice Shelf rheology preceding its disintegration inferred by a control method, Geophys. Res. Lett., 34, L19503, doi:10.1029/2007g1030980, 2007.

Khazendar, A., Rignot, E., and Larour, E.: Acceleration and spatial rheology of Larsen C Ice Shelf, Antarctic Peninsula, Geophys. Res. Lett., 38, L09502, doi:10.1029/2011g1046775, 2011.

Khazendar, A., Schodlok, M. P., Fenty, I., Ligtenberg, S. R. M., Rignot, E., and van den Broeke, M. R.: Observed thinning of Totten Glacier is linked to coastal polynya variability, Nature Communications, 4, 2857, doi:10.1038/Ncomms3857, 2013.

Khazendar, A., Borstad, C. P., Scheuchl, B., Rignot, E., and Seroussi, H.: The evolving instability of the remnant Larsen B Ice Shelf and its tributary glaciers, Earth Planet. Sc. Lett., 419, 199-210, doi:10.1016/j.epsl.2015.03.014, 2015. 
King, M. A. and Padman, L.: Accuracy assessment of ocean tide models around Antarctica, Geophys. Res. Lett., 32, L23608, doi:10.1029/2005g1023901, 2005.

Kuipers Munneke, P., Picard, G., van den Broeke, M. R., Lenaerts, J. T. M., and van Meijgaard, E.: Insignificant change in Antarctic snowmelt volume since 1979, Geophys. Res. Lett., 39, L01501, doi:10.1029/2011g1050207, 2012a.

Kuipers Munneke, P., van den Broeke, M. R., King, J. C., Gray, T., and Reijmer, C. H.: Near-surface climate and surface energy budget of Larsen C ice shelf, Antarctic Peninsula, The Cryosphere, 6, 353-363, doi:10.5194/tc-6-353-2012, 2012b.

Kuipers Munneke, P., Ligtenberg, S. R. M., van den Broeke, M. R., and Vaughan, D. G.: Firn air depletion as a precursor of Antarctic ice-shelf collapse, J. Glaciol., 60, 205-214, doi:10.3189/2014jog13j183, 2014.

Kulessa, B., Jansen, D., Luckman, A. J., King, E. C., and Sammonds, P. R.: Marine ice regulates the future stability of a large Antarctic ice shelf, Nat. Commun., 5, 3707, doi:10.1038/Ncomms4707, 2014.

Lenaerts, J. T. M., van den Broeke, M. R., van de Berg, W. J., van Meijgaard, E., and Munneke, P. K.: A new, high-resolution surface mass balance map of Antarctica (1979-2010) based on regional atmospheric climate modeling, Geophys. Res. Lett., 39, L04501, doi:10.1029/2011g1050713, 2012.

Luckman, A., Elvidge, A., Jansen, D., Kulessa, B., Munneke, P. K., King, J. C., and Barrand, N. E.: Surface melt and ponding on Larsen C Ice Shelf and the impact of foehn winds, Antarct. Sci., 26, 625-635, 2014.

Marshall, G. J., Orr, A., van Lipzig, N. P. M., and King, J. C.: The impact of a changing Southern Hemisphere Annular Mode on Antarctic Peninsula summer temperatures, J. Climate, 19, 53885404, doi:10.1175/Jcli3844.1, 2006.

McGrath, D., Steffen, K., Scambos, T., Rajaram, H., Casassa, G., and Lagos, J. L. R.: Basal crevasses and associated surface crevassing on the Larsen $\mathrm{C}$ ice shelf, Antarctica, and their role in ice-shelf instability, Ann. Glaciol., 53, 10-18, doi:10.3189/2012aog60a005, 2012.

McGrath, D., Steffen, K., Holland, P. R., Scambos, T., Rajaram, H., Abdalati, W., and Rignot, E.: The structure and effect of suture zones in the Larsen C Ice Shelf, Antarctica, J. Geophys. Res.Earth, 119, 588-602, doi:10.1002/2013jf002935, 2014.

Morris, E. M. and Vaughan, D. G.: Spatial and temporal variation of surface temperature on the Antarctic Peninsula and the limit of viability of ice shelves, Antarctic Peninsula Climate Variability, Hist. Paleoenviron. Perspect., 79, 61-68, 2003.

Mueller, R. D., Padman, L., Dinniman, M. S., Erofeeva, S. Y., Fricker, H. A., and King, M. A.: Impact of tidetopography interactions on basal melting of Larsen $\mathrm{C}$ Ice Shelf, Antarctica, J. Geophys. Res.-Oceans, 117, C05005, doi:10.1029/2011jc007263, 2012.

Nicholls, K. W., Pudsey, C. J., and Morris, P.: Summertime water masses off the northern Larsen C Ice Shelf, Antarctica, Geophys. Res. Lett., 31, L09309, doi:10.1029/2004g1019924, 2004.

Nicholls, K. W., Makinson, K., and Venables, E. J.: Ocean circulation beneath Larsen C Ice Shelf, Antarctica from in situ observations, Geophys. Res. Lett., 39, L19608, doi:10.1029/2012g1053187, 2012.

Padman, L., King, M., Goring, D., Corr, H., and Coleman, R.: Iceshelf elevation changes due to atmospheric pressure variations,
J. Glaciol., 49, 521-526, doi:10.3189/172756503781830386, 2003.

Padman, L., Costa, D. P., Dinniman, M. S., Fricker, H. A., Goebel, M. E., Huckstadt, L. A., Humbert, A., Joughin, I., Lenaerts, J. T. M., Ligtenberg, S. R. M., Scambos, T., and van den Broeke, M. R.: Oceanic controls on the mass balance of Wilkins Ice Shelf, Antarctica, J. Geophys. Res.-Oceans, 117, C01010, doi:10.1029/2011jc007301, 2012.

Paolo, F. S., Fricker, H. A., and Padman, L.: Volume loss from Antarctic ice shelves is accelerating, Science, doi:10.1126/science.aaa0940, in press, 2015.

Pritchard, H. D., Ligtenberg, S. R. M., Fricker, H. A., Vaughan, D. G., van den Broeke, M. R., and Padman, L.: Antarctic ice-sheet loss driven by basal melting of ice shelves, Nature, 484, 502-505, doi:10.1038/Nature10968, 2012.

Rignot, E., Casassa, G., Gogineni, P., Krabill, W., Rivera, A., and Thomas, R.: Accelerated ice discharge from the Antarctic Peninsula following the collapse of Larsen B ice shelf, Geophys. Res. Lett., 31, L18401, doi:10.1029/2004g1020697, 2004.

Rignot, E., Mouginot, J., and Scheuchl, B.: Ice Flow of the Antarctic Ice Sheet, Science, 333, 1427-1430, doi:10.1126/science.1208336, 2011.

Rye, C. D., Naveira Garabato, A. C., Holland, P. R., Meredith, M. P., Nurser, A. J. G., Hughes, C. W., Coward, A. C., and Webb, D. J.: Evidence of increased glacial melt in Antarctic coastal sea level rise, Nat. Geosci., 7, 732-735, doi:10.1038/ngeo2230, 2014.

Scambos, T. A., Hulbe, C., and Fahnestock, M.: Climate-induced ice shelf disintegration in the Antarctic Peninsula, Antarctic Peninsula Climate Variability, Hist. Paleoenviron. Perspect., 79, 79-92, 2003.

Scambos, T. A., Haran, T. M., Fahnestock, M. A., Painter, T. H., and Bohlander, J.: MODIS-based Mosaic of Antarctica (MOA) data sets: Continent-wide surface morphology and snow grain size, Remote Sens. Environ., 111, 242-257, doi:10.1016/j.rse.2006.12.020, 2007.

Shepherd, A., Wingham, D., Payne, T., and Skvarca, P.: Larsen Ice Shelf has progressively thinned, Science, 302, 856-859, doi:10.1126/science.1089768, 2003.

Shepherd, A., Wingham, D., and Rignot, E.: Warm ocean is eroding West Antarctic Ice Sheet, Geophys. Res. Lett., 31, L23402, doi:10.1029/2004g1021106, 2004.

Shepherd, A., Wingham, D., Wallis, D., Giles, K., Laxon, S., and Sundal, A. V.: Recent loss of floating ice and the consequent sea level contribution, Geophys. Res. Lett., 37, L13503, doi:10.1029/2010g1042496, 2010.

Shepherd, A., Ivins, E. R., Geruo, A., Barletta, V. R., Bentley, M. J., Bettadpur, S., Briggs, K. H., Bromwich, D. H., Forsberg, R., Galin, N., Horwath, M., Jacobs, S., Joughin, I., King, M. A., Lenaerts, J. T. M., Li, J. L., Ligtenberg, S. R. M., Luckman, A., Luthcke, S. B., McMillan, M., Meister, R., Milne, G., Mouginot, J., Muir, A., Nicolas, J. P., Paden, J., Payne, A. J., Pritchard, H., Rignot, E., Rott, H., Sorensen, L. S., Scambos, T. A., Scheuchl, B., Schrama, E. J. O., Smith, B., Sundal, A. V., van Angelen, J. H., van de Berg, W. J., van den Broeke, M. R., Vaughan, D. G., Velicogna, I., Wahr, J., Whitehouse, P. L., Wingham, D. J., Yi, D. H., Young, D., and Zwally, H. J.: A Reconciled Estimate of Ice-Sheet Mass Balance, Science, 338, 1183-1189, doi:10.1126/science.1228102, 2012. 
Tedesco, M.: Assessment and development of snowmelt retrieval algorithms over Antarctica from K-band spaceborne brightness temperature (1979-2008), Remote Sens. Environ., 113, 979997, doi:10.1016/j.rse.2009.01.009, 2009.

Trusel, L. D., Frey, K. E., Das, S. B., Munneke, P. K., and van den Broeke, M. R.: Satellite-based estimates of Antarctic surface meltwater fluxes, Geophys. Res. Lett., 40, 6148-6153, doi:10.1002/2013g1058138, 2013.

Turner, J., Barrand, N. E., Bracegirdle, T. J., Convey, P., Hodgson, D. A., Jarvis, M., Jenkins, A., Marshall, G., Meredith, M. P., Roscoe, H., Shanklin, J., French, J., Goosse, H., Guglielmin, M., Gutt, J., Jacobs, S., Kennicutt, M. C., Masson-Delmotte, V., Mayewski, P., Navarro, F., Robinson, S., Scambos, T., Sparrow, M., Summerhayes, C., Speer, K., and Klepikov, A.: Antarctic climate change and the environment: an update, Polar Record, 50, 237-259, doi:10.1017/S0032247413000296, 2014.
Valisuo, I., Vihma, T., and King, J. C.: Surface energy budget on Larsen and Wilkins ice shelves in the Antarctic Peninsula: results based on reanalyses in 1989-2010, The Cryosphere, 8, 15191538, doi:10.5194/tc-8-1519-2014, 2014.

van den Broeke, M.: Strong surface melting preceded collapse of Antarctic Peninsula ice shelf, Geophys. Res. Lett., 32, L12815, doi:10.1029/2005g1023247, 2005.

van der Veen, C. J.: Fracture mechanics approach to penetration of surface crevasses on glaciers, Cold Reg. Sci. Technol., 27, 31-47, doi:10.1016/S0165-232x(97)00022-0, 1998.

Vieli, A., Payne, A. J., Shepherd, A., and Du, Z.: Causes of precollapse changes of the Larsen B ice shelf: Numerical modelling and assimilation of satellite observations, Earth Planet. Sc. Lett., 259, 297-306, doi:10.1016/j.epsl.2007.04.050, 2007.

Wingham, D. J., Wallis, D. W., and Shepherd, A.: Spatial and temporal evolution of Pine Island Glacier thinning, 1995-2006, Geophys. Res. Lett., 36, L17501, doi:10.1029/2009g1039126, 2009. 